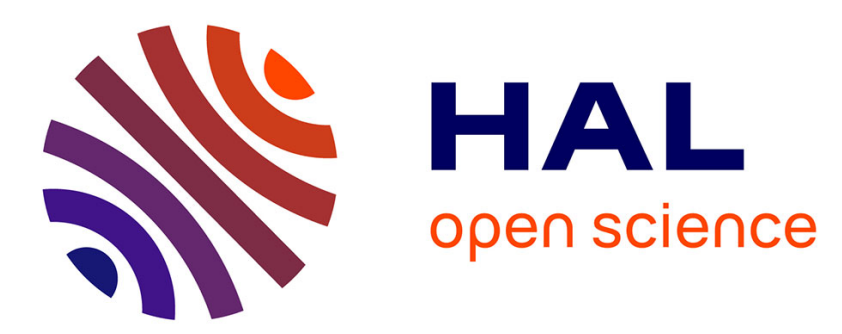

\title{
A Person-Centered Perspective on the Combined Effects of Global and Specific Levels of Job Engagement
}

Nicolas Gillet, Alexandre J.S. Morin, Christine Jeoffrion, Evelyne Fouquereau

\section{To cite this version:}

Nicolas Gillet, Alexandre J.S. Morin, Christine Jeoffrion, Evelyne Fouquereau. A Person-Centered Perspective on the Combined Effects of Global and Specific Levels of Job Engagement. Group and Organization Management, 2020, 45 (4), pp.556-594. 10.1177/1059601119899182 . hal-03142256

\section{HAL Id: hal-03142256 https://hal.science/hal-03142256}

Submitted on 15 Feb 2021

HAL is a multi-disciplinary open access archive for the deposit and dissemination of scientific research documents, whether they are published or not. The documents may come from teaching and research institutions in France or abroad, or from public or private research centers.
L'archive ouverte pluridisciplinaire HAL, est destinée au dépôt et à la diffusion de documents scientifiques de niveau recherche, publiés ou non, émanant des établissements d'enseignement et de recherche français ou étrangers, des laboratoires publics ou privés. 
Running Head: Job Engagement Profiles

\title{
A Person-Centered Perspective on the Combined Effects of Global and Specific Levels of Job
} Engagement

Nicolas Gillet*, Université de Tours, QualiPsy EE 1901, Tours, France

Alexandre J.S. Morin*, Substantive Methodological Synergy Research Laboratory, Department of Psychology, Concordia University, Montreal, Canada

Christine Jeoffrion, Université de Nantes, LPPL EA 4638, Nantes, France

Evelyne Fouquereau, Université de Tours, QualiPsy EE 1901, Tours, France

* The first two authors (N.G. \& A.J.S.M.) contributed equally to this article and their order was determined at random: Both should thus be considered first authors.

Corresponding author

Nicolas Gillet, Université de Tours,

UFR Arts et Sciences Humaines,

Département de psychologie,

3 rue des Tanneurs, 37041 Tours Cedex 1, France

E-mail: nicolas.gillet@univ-tours.fr

This is the prepublication version of the following manuscript:

Gillet, N., Morin, A. J. S, Jeoffrion, C., \& Fouquereau, E. (in press). A person-centered perspective on the combined effects of global and specific levels of job engagement. Group \& Organization Management. Early view. doi: 10.1177/1059601119899182

This paper is not the copy of record and may not exactly replicate the authoritative document published in Group \& Organization Management.

\begin{abstract}
The present study examines how the different dimensions of job engagement combine within different profiles of workers $(n=264)$. This research also documents the relations between the identified job engagement profiles, demographic characteristics (gender, age, education, working time, and organizational tenure), job characteristics (work autonomy, task variety, task significance, task identity, and feedback), attitudes (affective and normative commitment) and psychological health (emotional exhaustion and ill-being). Latent profile analysis revealed four profiles of employees defined based on their global and specific (physical, emotional, and cognitive) job engagement levels: Globally Disengaged, Globally Engaged, Globally but not Emotionally Engaged, and Moderately Engaged. Employees' perceptions of task variety and feedback shared statistically significant relations with their likelihood of membership into all latent profiles. Profiles were finally showed to be meaningfully related to employees' levels of affective commitment, normative commitment, emotional exhaustion, and ill-being.

Keywords: Job engagement; Latent profiles; Job characteristics; Organizational commitment; Burnout
\end{abstract}


Organizational researchers have shown considerable interest in achieving a better understanding of the nature, structure, and benefits associated with employee engagement at work (Shuck, Nimon, \& Zigarmi, 2017; Zhong, Wayne, \& Liden, 2016). Kahn (1990) described job engagement as a motivational construct reflecting employees' active harnessing of personal resources toward work-related tasks. Scholars and practitioners suggest that job engagement can be leveraged by organizations to create a competitive advantage (Macey \& Schneider, 2008). Despite this high level of scientific attention and assumed benefits, widespread differences in opinion exist regarding the definition, conceptual underpinnings, and measurement of engagement (Crawford, LePine, \& Rich, 2010; Nimon, Shuck, \& Zigarmi, 2016). Yet, although operational definitions of engagement have evolved since Khan's (1990) seminal proposal and often differ across studies, Christian, Garza, and Slaughter (2011) noted that employee's engagement was usually taken to reflect "high levels of personal investment in the work tasks performed on a job" (p. 89).

Arguably, the most popular measure of engagement at the moment is the Utrecht Work Engagement Scale (UWES; Schaufeli \& Bakker, 2004). The UWES assesses the construct of work engagement, defined around the three components of vigor, dedication, and absorption. However, whereas Kahn's (1990) initial conceptualization explicitly defined job engagement as the degree to which individuals invest their physical, emotional, and cognitive energy into their work performance, Rich, LePine, and Crawford (2010) rightfully noted that the UWES rather seemed to focus on antecedent conditions to this high investment of personal resources. This recognition led them to propose an alternative measure, the Job Engagement Scale (JES), focusing more directly on the construct of job engagement as initially defined by Kahn (1990) and spanning physical, emotional, and cognitive dimensions. Importantly, in a recent comparative investigation of both measures across five independent samples of participants, Byrne, Peters, and Weston (2016) found results that supported the distinct nature of these two measures and highlighted the greater degree of conceptual overlap between the UWES (relative to the JES) and other measures of job attitudes (also see Newman \& Harrison, 2008; Wefald, Reichards, \& Serrano, 2011). Finally, yet another attempt was made by May, Gilson, and Harter (2004) to asses psychological engagement as a function of Kahn's (1990) model. However, results from principal components analysis of their initial 24 items did not reveal three separate and reliable factors reflecting cognitive, emotional, and physical engagement. They thus chose to rely on a global 13 -item scale that demonstrated good reliability and had some balance across the three components of job engagement.

Despite abundant research supporting the idea that a variety of desirable outcomes are associated with these three (physical, emotional, and cognitive) components of job engagement (Shuck et al., 2017), little is known about their combined impact (Shuck, Zigarmi, \& Owen, 2015). Two different approaches can be used to investigate the combined impact of these three facets of job engagement. Variable-centered analyses, designed to test how variables relate to other variables, are able to test for interaction effects (i.e., if the effect of a predictor differs as a function of another variable referred to as a moderator). However, these traditional approaches are unable to clearly depict the joint effect of variable combinations involving more than two or three interacting predictors, and become even more complex to interpret when relations display some nonlinearity. In contrast, through their focus on the identification of subpopulations of workers characterized by distinct configurations, or profiles, on a set of variables, person-centered analyses are more naturally suited to the consideration of the joint effect of variable combinations.

To the best of our knowledge, very little person-centered research has considered how engagement dimensions combine within specific individuals, and none of this research has focused on job engagement as assessed by the JES. Moreover, although these limited person-centered studies have generated insights into the nature and implications of the engagement construct, they also led to divergent conclusions regarding the importance of the various components of engagement. For instance, and contrary to theoretical predictions (Schaufeli \& Bakker, 2004), Gillet, Caesens, Morin, and Stinglhamber (2019) showed that there might be benefits associated with the ability to maintain a healthy distance from work (i.e., low levels of absorption) among workers presenting a high level of work engagement (as measured with the UWES). In other words, there might be limits to the benefits associated with very high levels of work engagement. This interpretation is aligned with the possible "dark side" of work engagement alluded to by Sonnentag (2011), and supported by Caesens, Stinglhamber, and Marmier (2016) who demonstrated curvilinear (inverted U-shape) relations 
between work engagement and turnover intentions. It is interesting to note that this interpretation is also aligned with research on the concept of over-commitment (e.g., Siegrist et al., 2004), showing that whereas employees' commitment tends to be associated with a variety of positive work outcomes (e.g., Meyer, Stanley, Herscovitch, \& Topolnytsky, 2002), extreme levels may be more problematic (Morin, Vandenberghe, Turmel, Madore, \& Maïano, 2013). Obviously, research is needed to confirm these previous findings and to see whether and how they extend to the job engagement construct initially defined by Kahn (1990) and operationalized in the JES.

More generally, information is still lacking regarding the nature and effects of employees' most frequent configurations of job engagement. To inform this issue, the present study seeks to identify profiles of employees characterized by distinct job engagement configurations. Indeed, person-centered analyses provide a way of considering the combined effects of the job engagement components, allowing for the identification of profiles of employees characterized by different configurations of job engagement dimensions (Meyer \& Morin, 2016). More importantly, the present study does so while taking into account the inherent multidimensionality of job engagement through the simultaneous consideration of employees' global and specific (physical, cognitive, and emotional) levels of job engagement (e.g., Gillet, Caesens et al., 2019). In addition, this study seeks to document the construct validity of the job engagement profiles by considering their associations with a series of determinants (gender, level of education, working time, organizational tenure, work autonomy, task variety, task significance, task identity, and feedback) and outcomes (affective and normative organizational commitment, emotional exhaustion, and ill-being). In practical terms, the present results are likely to have important practical implications as the personcentered approach is known to show a greater level of alignment with professionals and managers natural tendency to think in terms of categories rather than complex variable relations (Meyer \& Morin, 2016; Morin, Morizot, Boudrias, \& Madore, 2011; Zyphur, 2009). Thus, by relying on the results from this study, managers might be able to build appropriate intervention strategies targeting distinct types of employees that might suffer from a lack of job engagement.

\section{On the Desirable Effects of Job Engagement}

Given its role as a psychological resource for employees (Halbesleben, 2010), it is not surprising to note that previous variable-centered research has shown job engagement to be associated with a variety of outcome variables known to be beneficial for both the organization (e.g., lower levels of turnover intentions; Zhong et al., 2016) and the employee (e.g., higher job satisfaction and well-being; Park, Kim, Yoon, \& Joo, 2017). More specifically, Shuck and Reio Jr. (2014) showed that employees with high levels of job engagement demonstrated higher levels of personal accomplishment and psychological well-being than those with low levels of job engagement, who demonstrated higher levels of emotional exhaustion and depersonalization. Many theoretical arguments have been offered to account for the positive consequences of job engagement. For instance, workers with high levels of job engagement focus their physical effort on the pursuit of role-related goals. They are also cognitively vigilant and emotionally connected to the endeavor (Ashforth \& Humphrey, 1995). Moreover, job engagement facilitates the accomplishment of organizationally valued behaviors, promotes behavior that is more attentive, focused, and vigilant, and helps workers meet the emotional demands of their roles (Kahn, 1990). Finally, job engagement is associated with the promotion of increased connection among employees in pursuit of organizational goals (Ashforth \& Humphrey, 1995). In contrast, workers with low levels of job engagement withhold their physical, cognitive, and emotional energies, and their work is passive, robotic, and detached (Kahn, 1990), thus leading to more negative outcomes (e.g., high levels of emotional exhaustion and ill-being, low levels of organizational commitment).

\section{An Integrated Representation of the Globality and Specificity of Job Engagement}

Despite the recognition that a complete assessment of job engagement should tap into the physical, emotional, and cognitive dimensions (Kahn, 1990), it has been proposed that employees might experience job engagement in a more holistic manner as a single overarching job engagement dimension (Crawford et al., 2010; May et al., 2004). This global approach is supported by the observation of high correlations among ratings of physical, emotional, and cognitive job engagement (Rich et al., 2010), and by the fact that a higher-order representation of job engagement tends to relate more strongly to antecedents and 
outcomes than its first-order components (Shuck et al., 2017). However, research has also revealed differentiated associations between these three dimensions and a variety of outcome variables, thus supporting the existence of conceptually-distinct physical, emotional, and cognitive dimensions of job engagement (e.g., Shuck et al., 2017). Yet, a third option also exists according to which job engagement might exist as a global entity reflecting commonalities among ratings of physical, emotional, and cognitive engagement, which themselves may include specificity unexplained by this global entity. Rich et al.'s (2010) higher-order results support the idea that ratings of physical, emotional, and cognitive engagement are conceptually-related dimensions of a global job engagement construct. However, one remaining question is whether sufficient specificity exists in the physical, emotional, and cognitive dimensions once global job engagement is taken into account (Morin, Boudrias et al., 2016, 2017).

Psychometrically, two approaches can be used to study this question. The most typical of these approaches relies on hierarchical models (e.g., Rich et al., 2010). In hierarchical models, ratings on specific indicators are used to define first-order factors (physical, emotional, and cognitive), which are then used to define a higher-order factor (global job engagement). Hierarchical models suffer from one important limitation: They rely on a rigid proportionality constraint forcing the ratio of variance explained by the global factor relative to that explained by the specific factors to be exactly the same for all items associated with a specific first-order factor (Gignac, 2016; Morin, Arens, \& Marsh, 2016; Reise, 2012). Bifactor models provide a flexible alternative not limited by this unrealistic constraint (Chen, West, \& Sousa, 2006). In a bifactor model, one Global (G) factor (global job engagement) and a series of orthogonal Specific (S) factors (physical, emotional, and cognitive) are used to explain the covariance among a set of items. Bifactor models directly test the presence of a global unitary construct underlying the answers to all items (G-Factor, reflecting global job engagement levels) and whether this global construct co-exists with meaningful specificities (S-Factors, reflecting the extent to which levels on the specific facets deviate from the global level) not explained by the G-Factor.

When considering bifactor models, it is important to keep in mind that their only true difference with higher-order factor models is related to the presence of this rigid proportionality constraint such that it is possible, from a higher-order factor model, to obtain an equivalent bifactor solution by the simple multiplication of higher-order factor loadings by first-order factor loadings (i.e., the Schmid-Leiman transformation; Morin, Arens, \& Marsh, 2016; Reise, 2012). Furthermore, when this proportionality constraints is found to hold with the data, these two representations are fully equivalent (Jennrich \& Bentler, 2011). Thus, both approaches: (a) involve the estimation of first-order factors or S-factors that are orthogonal and conditional on the integration of the higher-order factor or G-factor to the model; (b) estimate the variance shared across all items via the estimation of a single higher-order factor or G-factor; and (c) estimate the variance that is unique to a specific subscale as part of the disturbance (or residuals) of the first-order factors or the S-factors, although this estimation is more direct in the bifactor model. Importantly, this last element (c) leads to a critical disadvantage of the higher-order approach when used to generate factor scores for subsequent analyses. More precisely, this indirect disaggregation of the variance uniquely associated with the first-order factors as part of the first-order residuals rather than firstorder factors themselves leads to conceptual redundancies in these secondary analyses which can easily be solved by the reliance on a bifactor approach (Morin, Boudrias et al., 2016, 2017). Thus, bifactor models provide a way to simultaneously consider both the forest (i.e., global job engagement) and the trees (i.e., the specificities associated with physical, emotional, and cognitive engagement) (Tóth-Király, Morin, Böthe, Orosz, \& Rigó, 2018). We adopt this approach in the present study.

\section{A Complementary Person-Centered Perspective}

Variable-centered analyses, such as the approaches used in the studies presented thus far, operate under the assumption that all participants are drawn from a single population for which a single set of "average" parameters can be estimated. Although such analyses provide a way to assess interaction effects among variables, such results are especially hard to interpret when they involve more than two or three interacting predictors (i.e., the application of a bifactor approach would result in the need to consider four interacting predictors: One G-factor and three S-factors). Further, interaction effects assume that the influence of one target variable fluctuates in a linear manner as a function of the other variable. Even though polynomial 
models can incorporate non-linear parameters (Edwards, 2009), it is almost impossible to interpret such models when more than two interacting predicting variables are at play.

An even more direct way of looking at the combined effects of job engagement facets involves personcentered analyses, allowing for the identification of employees' profiles characterized by different configurations of job engagement dimensions (Meyer \& Morin, 2016). In contrast to variable-centered analyses, person-centered analyses seek to identify qualitatively distinct subpopulations, or profiles, sharing similar configurations of job engagement components. Of particular relevance, the estimation of latent profiles based on indicators capturing the possible bifactor structure of job engagement ratings (i.e., based on a proper disaggregation of global job engagement levels from the specific physical, emotional, and cognitive facets) would make it possible to identify clearer, and more easily interpretable, profiles differing from one another in relation to both the global component (i.e., global job engagement) and to the more specific components (physical, emotional, and cognitive) (Morin, Boudrias et al., 2016, 2017). Importantly, ignoring this dual global/specific structure caries the risk of identifying inaccurate profiles characterized by job engagement levels solely capturing that global component and ignoring the more meaningful differences located at the specific facet level (Morin, Boudrias et al., 2016, 2017). In the present study, we apply this approach to the identification of job engagement profiles. Precisely, this research assesses how global levels of job engagement operate in combination with specific levels of physical, emotional, and cognitive job engagement among distinct profiles of employees.

Due to the absence of prior research using latent profile analyses (LPA) to identify job engagement profiles assessed with the JES (Rich et al., 2010), it is difficult to specify hypotheses about the nature and number of the expected profiles. However, different sources of indirect evidence can still be used to guide the present investigation.

Variable-centered studies using the UWES. A first source of indirect evidence comes from research conducted using the UWES (Schaufeli \& Bakker, 2004), for which researchers have started to highlight the importance of considering the combined impact of the work engagement dimensions assessed with this instrument (Mäkikangas \& Kinnunen, 2016; Mäkikangas, Kinnunen, Feldt, \& Schaufeli, 2016). Unfortunately, most of these studies have tried to identify profiles from the combinations of work engagement indicators and additional variables (burnout: Mäkikangas, Hyvönen, \& Feldt, 2017; workaholism and burnout: Innanen, Tolvanen, \& Salmela-Aro, 2014; workaholism, burnout, and job satisfaction: Mäkikangas et al., 2015). These studies thus make it impossible to isolate the effects of the different work engagement configurations net of the effects of the additional variables. Furthermore, most of these studies only considered global levels of work engagement without considering the specificities associated with the work engagement facets.

Person-centered studies using the UWES. We located two person-centered studies focusing on the identification of work engagement configurations as assessed with the UWES. In a first study, Simbula, Guglielmi, Schaufeli, and Depolo (2013) relied on cluster analyses to identify teachers' profiles of work engagement based of their levels of vigor, dedication, and absorption. Their results revealed two distinct profiles characterized by high (61.2\% of the participants) or moderate (38.8\% of the participants) levels of vigor, dedication, and absorption. They also found that highly engaged participants showed higher levels of personal development, work-family balance, self-efficacy, job satisfaction, altruism, and civic virtue, and lower levels of health problems relative to moderately engaged participants. These profiles, estimated based on typical scale scores, only display level differences, possibility due to their failure to properly disaggregate global ratings of work engagement from the specificity inherent in the vigor, absorption, and dedication subscales. In addition, this study was limited by its reliance on a sample of teachers, making it hard to assess whether these results would generalize to more diversified samples.

In a second study, Gillet, Caesens et al. (2019) relied on LPA conducted on the basis of profile indicators (i.e., factors scores taken from a bifactor model) allowing them to distinguish global levels of work engagement properly disaggregated from the specific levels of vigor, absorption, and dedication among a sample of 730 employees recruited from a variety of organizations. Their results first revealed a large normative profile of employees characterized by average global and specific levels of work engagement (74.59\%), accompanied by four additional profiles presenting disengaged-vigorous (7.24\%), 
totally disengaged (7.36\%), vigorously absorbed (7.26\%), and engaged yet distanced $(3.55 \%)$ configurations of work engagement. These profiles also showed a high level of stability and similarity across a four-month period, and meaningful associations with participants' levels of health, stress, job satisfaction, and intentions to leave the organization.

Person-centered studies on related-constructs. Indirect evidence coming from research conducted on the related-constructs of psychological health and well-being is also informative. For instance, Morin, Boudrias et al. (2017) demonstrated the superiority of a bifactor representation of employees' ratings of psychological well-being at work. Then, relying on bifactor factor scores, results from their LPA revealed four distinct profiles of employees: (1) a large (59.4\%) normative profile characterized mainly by an average global level of psychological well-being and matching levels across specific dimensions (i.e., interpersonal fit, competence, thriving, involvement, and recognition); (2) an intrinsically-driven profile (29.2\%); (3) an ill-adjusted extrinsically-driven profile (6.6\%); and (4) a well-integrated profile (4.8\%). Similarly, Morin, Boudrias et al.'s (2016) results supported a bifactor representation of employees' ratings of psychological health at work (encompassing ratings of well-being and distress). Results from their LPA then revealed a similar five-profile solution including: (a) a large $(61.0 \%)$ normative profile showing average of psychological health across dimensions; (b) an adapted profile (11.1\%); (c) a flourishing profile (1.38\%; similar to the previously described well-integrated profile); (d) a stressfully-involved profile (14.3\%; similar to the previously described ill-adjusted extrinsically-driven profile); and (e) a harmoniously-distanced profile (12.3\%).

The present study. When considering these results, it is interesting to note both the similarity across studies, and the fact that failure to control for construct-relevant psychometric multidimensionality related to coexisting global and specific constructs may erroneously lead to the identification of leveldifferentiated profiles. Indeed, Morin, Boudrias et al.'s $(2016,2017)$ studies both revealed that profiles identified based on typical first-order factor scores tended to present almost pure level differences similar to the results obtained by Simbula et al. (2013), whereas profiles based on bifactor factor scores were far more similar to those reported by Gillet, Caesens et al. (2019). In the present study, we apply the methodological framework proposed by Morin, Boudrias et al. $(2016,2017)$ in order to extend to the job engagement area results obtained by Simbula et al. (2013) and Gillet, Caesens et al. (2019) in research on the work engagement construct. We previously noted that person-centered solutions are a natural candidate for practical interventions focused on specific categories of employees due to their alignment with managers' natural tendencies to think in terms of categories (e.g., Zyphur, 2009). Unfortunately, the current lack of research clarity makes it hard to devise such interventions, a limitation that we seek to address in the present study.

In the absence of prior guidance from job engagement research relying on the JES and/or adopting a proper disaggregation of global versus specific ratings of job engagement in the identification of employees' profiles, we leave as an open research question the expected nature of the profiles that will be identified. However, in line with the consistency of results obtained by Morin, Boudrias et al. (2016, 2017) and Gillet, Caesens et al. (2019) in the study of psychological health, well-being, and work engagement, we expect at least a moderately engaged profile characterized by average levels of job engagement across dimensions, a well-integrated (highly engaged) profile characterized by globally low levels of job engagement across dimensions, and an ill-adjusted (totally disengaged) profile characterized by globally low levels of job engagement across dimensions. In addition, we also expect additional profiles presenting well-differentiated configurations of job engagement across indicators. For instance, we expect a profile characterized by high global levels of job engagement, average levels of physical and cognitive job engagement, and low levels of emotional job engagement, sharing similarities with the engaged yet distanced profile identified by Gillet, Caesens et al. (2019).

\section{A Person-Centered Construct Validation Perspective}

To document the theoretical and practical implications of the most frequent combinations reflected in the job engagement profiles to be identified in this study, we adopt a construct validation perspective (e.g., Meyer \& Morin, 2016; Morin \& Wang, 2016) focused on documenting the associations between these profiles and a variety of covariates. Indeed, having access to the most commonly occurring configurations 
of job engagement among employees, despite its intrinsic interest, is of little value for managerial practice without accompanying knowledge regarding possible determinants and outcomes of these configurations. In the present study, we first focused on the role of demographic (gender, education, working time, and organizational tenure) and job (work autonomy, task variety, task significance, task identity, and feedback) characteristics in the prediction of profile membership.

Demographic characteristics as predictors. Knoll and Redman (2016) showed that age and gender were not significantly related to job engagement. Additional research similarly revealed a lack of associations between job engagement and employees' tenure, gender, age or education (Haynie, Mossholder, \& Harris, 2016; Park et al., 2017; Zhong et al., 2016). These considerations suggest that these demographic characteristics (gender, level of education, working time, and organizational tenure) should be unrelated to the likelihood of membership into any of the job engagement profiles. Observing such a lack of relations would support the discriminant validity of the profiles.

Job characteristics. Despite the well-documented importance of job characteristics in the prediction of a variety of desirable outcome variables (Marinova, Peng, Lorinkova, Van Dyne, \& Chiaburu, 2015), to the best of our knowledge, no research has yet examined the effects of job characteristics on job engagement. Nevertheless, some attention has been paid to the effects of job characteristics on conceptually-related constructs, namely the vigor, dedication, and absorption components of work engagement as assessed with the UWES. More precisely, the desirable effects of various job resources (i.e., work autonomy, task variety, task significance, task identity, and feedback) have been widely documented in relation to outcomes such as work engagement (Bakker, Demerouti, \& Sanz-Vergel, 2014; Brauchli, Schaufeli, Jenny, Füllemann, \& Bauer, 2013). Taken together, these prior variable-centered studies suggest that the job characteristics of work autonomy, task variety, task significance, task identity, and feedback should also should predict membership into the job engagement profiles. More precisely, we expect more positive job characteristics (i.e., enriched jobs; Hackman \& Oldham, 1976) to predict a higher likelihood of membership into the profiles characterized by higher global levels of job engagement.

Observing such relations would thus support the convergent validity of the profiles.

Outcomes of profile membership. We also consider how the identified job engagement profiles would related to a series of outcome variables related to employees' attitudes (affective and normative organizational commitment) and psychological health (emotional exhaustion and ill-being), retained based on research evidence showing that they present significant associations with job engagement (Knoll \& Redman, 2016; Shuck et al., 2017). In addition to presenting well-documented links with job engagement, these outcomes were also selected based on mounting research evidence supporting their important role in work performance (e.g., Demerouti, Bakker, \& Leiter, 2014; Huang \& Simha, 2017). For instance, employees' affective organizational commitment plays an important role in the work setting and numerous studies have shown that affective commitment is an important predictor of job performance (e.g., Morin et al., 2013; Morin, Morizot et al., 2011). Similarly, employees' level of emotional exhaustion represents another well-documented predictor of work performance and persistence (e.g., Marchand \& Vandenberghe, 2016; Yagil \& Medler-Liraz, 2017). Although the assumption that the identified latent profiles will demonstrate construct validity lead us to expect well-differentiated relations between the identified job engagement profiles and the covariates considered in this study, the lack of previous research conducted in this area makes it hard to provide more specific hypotheses in this regard. Indeed, although Simbula et al. (2013) and Gillet, Caesens et al. (2019) did not consider the specific covariates assessed in this study (affective and normative organizational commitment, emotional exhaustion, and illbeing), the nature of the profiles identified in their study only allows us to expect profiles characterized by higher levels of job engagement to be associated with more adaptive functioning (e.g., higher affective organizational commitment, lower ill-being) than profiles characterized by lower levels of engagement. Observing well-differentiated relations between the job engagement profiles and outcomes measures would support both the convergent and discriminant validity of the profiles.

\section{The Present Study}

In sum, the present study is a substantive-methodological synergy (Marsh \& Hau, 2007) in which we seek to illustrate the value of a methodological framework proposed by Morin, Boudrias et al. (2016, 
2017) to better capture the underlying multidimensionality of the job engagement construct. This approach relies on the combination of the variable-centered bifactor framework to better capture the inherent duality of employees' global and specific job engagement levels with a person-centered approach seeking to identify the most commonly occurring job engagement configurations defined while accounting for the dual global and specific nature of this construct. As such, this study has broad relevance to the managerial and organizational sciences by providing the illustration of a comprehensive variable- and person-centered framework which may be equally applied to investigate the structure of a variety of psychological constructs similarly conceptualized as a series of subdimensions nested within a single global entity. Substantively, this study contributes to research on the job engagement construct by: (a) investigating its dual global and specific nature in an attempt to resolve discrepant conclusions regarding its optimal operationalization; (b) identifying the most commonly occurring configurations of job engagement among employees while relying on an optimized representation of the underlying multidimensional structure of this construct; and (c) documenting the practical value of these configurations, or profiles, by formally assessing their associations with key predictor and outcome variables.

\section{Participants and Procedures}

\section{Method}

Research assistants distributed a paper-based questionnaire to a sample of 264 workers (118 men and 146 women). These workers were recruited in a convenience sample of organizations (e.g., public hospitals, industries, sales, and services), all located in France, who agreed to participate in this study when contacted by the research assistant who provided them with a short description of the study. In each organization, employee participation was voluntary and respondents were ensured that their responses would be kept confidential. Before proceeding with the data collection, participants in each organization received a survey packet including the questionnaire, a cover letter explaining the objectives, and a consent form stressing the anonymous and voluntary nature of participation. Questionnaires completion took about 20 minutes. Completed questionnaires were directly returned to the research assistants. No incentive was offered to take part in the study. All questionnaires were administered in French and instruments not already available in this language (i.e., job engagement and ill-being) were adapted to French using a standardized back-translation procedure (Hambleton, 2005; van de Vijver \& Hambleton, 1996) by a panel of independent bilingual experts (i.e., distinct individuals were involved in the translation and back-translation, and differences were resolved by consensus).

Respondents were aged between 21 and 63 years $(M=36.81, S D=11.60)$ and had an average organizational tenure of 9.65 years $(S D=9.92)$. In terms of education, $2.7 \%$ of the participants had no diploma, $25.4 \%$ completed vocational training, $15.5 \%$ completed high school, and 56.4\% completed university. Finally, $83.0 \%$ of the participants worked full-time.

\section{Measures}

Job engagement. The JES (Rich et al., 2010) was used to assess job engagement. This instrument includes three subscales assessing physical (six items; $\alpha=.87$; e.g., "I work with intensity on my job"), emotional (six items; $\alpha=.92$; e.g." "I am enthusiastic in my job"), and cognitive (six items; $\alpha=.91$; e.g., "At work, my mind is focused on my job") job engagement. These items were rated on a five-point Likert-type scale ranging from 1 (strongly disagree) to 5 (strongly agree).

Job characteristics. Work autonomy (nine items; $\alpha=.91$; e.g., "The job allows me to make a lot of decisions on my own"), task variety (four items; $\alpha=.92$; e.g., "The job involves doing a number of different things"), task significance (four items; $\alpha=.78$; e.g., "The job has a large impact on people outside the organization"), task identity (four items; $\alpha=.82$; e.g., "The job allows me to complete work I start"), and feedback (three items; $\alpha=.86$; "The job itself provides me with information about my performance") were measured with subscales from the French version of the Work Design Questionnaire (Bigot et al., 2014; Morgeson \& Humphrey, 2006). Items were rated on a seven-point Likert-type scale ranging from 1 (strongly disagree) to 7 (strongly agree).

Emotional exhaustion. Emotional exhaustion was assessed with the French version of the five-item scale ( $\alpha=.88$; e.g., "I feel emotionally drained by my work") from the Maslach Burnout Inventory-General Survey (Lapointe, Vandenberghe, \& Boudrias, 2013; Schaufeli, Leiter, Maslach, \& Jackson, 1996). Items were rated on a 1 (strongly disagree) to 5 (strongly agree) scale. 
Commitment to the organization. The French version (Lapointe et al., 2013) of Meyer, Allen, and Smith's (1993) scale was used to assess affective (six items; $\alpha=.91$; e.g., "I feel like part of the family at my organization") and normative (six items; $\alpha=.93$; e.g., "It would not be morally right for me to leave this organization now") commitment to the organization. Items were rated on a five-point Likert-type scale (1 strongly disagree; 5 - strongly agree).

Ill-being. Ill-being was assessed with six items ( $\alpha=.89$; e.g., "tense", "worried") from Warr's (1990) measure on which participants were asked to indicate how often they experienced each emotion in the past week when thinking about their job on a five-point scale (1 - never; 5 -always).

\section{Model Estimation}

\section{Analyses}

All analyses were conducted using Mplus 8 (Muthén \& Muthén, 2017) robust Maximum Likelihood (MLR) estimator. This estimator provides parameter estimates, standard errors, and fit indices that are robust to the non-normality of the response scales used in the present study (Finney \& DiStefano, 2013). These models were estimated with Full Information Maximum Likelihood (FIML; Enders, 2010) to handle the few missing responses present at the item level (0.00-1.52\%).

\section{Preliminary Analyses}

Rather than using scale scores (the mean or sum of items) to estimate the profiles and their relations with covariates, we relied on factor scores saved from preliminary measurement models (for details on the advantages of factor scores in LPA, see Meyer \& Morin, 2016; Morin, Meyer, Creusier, \& Biétry, 2016). Factor scores do not control for unreliability as well as latent variables, but provide a partial control for measurement errors by giving more weight to more reliable items (Skrondal \& Laake, 2001) and preserve the underlying nature of the measurement model better than scale scores (Morin, Boudrias et al., 2016, 2017). For the job engagement measure, factor scores were saved from a bifactor exploratory structural equation model (ESEM; Morin, Arens, \& Marsh, 2016). Bifactor-ESEM models provide a way to achieve a complete disaggregation of participants' ratings into one global component reflecting the variance shared across all items, and into specific components reflecting the variance shared among items forming a dimension but not already explained by the G-factor, while taking into account the imperfect nature of indicators associated with conceptually-related constructs (Morin, Arens, \& Marsh, 2016; Reise, 2012). In this model, all items were allowed to simultaneously load on one G-factor reflecting global levels of job engagement, and on three Sfactors corresponding to specific levels of physical, emotional, and cognitive job engagement. Cross-loadings were allowed between the S-factors using an orthogonal bifactor target rotation in line with bifactor assumptions (Morin, Arens, \& Marsh, 2016; Reise, 2012). Target rotation allows for the estimation of ESEM models in a confirmatory manner, based on user-defined main factor indicators, and requirement for cross-loadings to be estimated as close to zero as possible (Morin, Arens, \& Marsh, 2016). In particular, the statistical research literature has recently demonstrated that the exclusion of cross-loadings (even as small as .100), but not their unnecessary inclusion, was likely to result in biases in the estimation of latent constructs (e.g., Asparouhov, Muthén, \& Morin, 2015). Finally, Morin, Boudrias et al. (2016, 2017) showed that when global constructs (i.e., job engagement) co-exist with specific dimensions (i.e., physical, emotional, and cognitive), failure to control for this globality in person-centered analyses may mistakenly result in the identification of profiles differing from one another quantitatively (i.e., matching levels across indicators) rather than qualitatively (i.e., distinct configurations). Details on these measurement models, which proved superior to alternatives, are reported in the online supplements.

\section{Person-Centered Analyses}

LPA were estimated using the job engagement factor scores as profile indicators. We examined solutions including one to eight latent profiles in which the means and variances of the job engagement factor scores were freely estimated in all profiles (Diallo, Morin, \& Lu, 2016; Peugh \& Fan, 2013). LPA were conducted using 5000 random sets of start values, 1000 iterations, and retaining the 200 best solutions for final optimization (Hipp \& Bauer, 2006). To determine the optimal number of profiles, multiple sources of information were considered, including the substantive meaningfulness, theoretical conformity, and statistical adequacy of the solutions (Marsh, Lüdtke, Trautwein, \& Morin, 2009; Morin, 2016; Muthén, 2003). In addition, statistical indices can support this decision (McLachlan \& Peel, 2000): (i) the Akaïke 
Information Criterion (AIC), (ii) the Consistent AIC (CAIC), (iii) the Bayesian Information Criterion (BIC), (iv) the sample-size Adjusted BIC (ABIC), (v) the standard and adjusted Lo, Mendell and Rubin's (2001) Likelihood Ratio Tests (LMR/aLMR; as these tests typically yield the same conclusions, we only report the aLMR), and (vi) the Bootstrap Likelihood Ratio Test (BLRT). A lower value on the AIC, CAIC, BIC, and ABIC suggests a better-fitting model. The aLMR and BLRT compare a $k$-class model with a $k$-1-class model. A significant $p$ value indicates that the $k$ - 1 -class model should be rejected in favor of a $k$-class model. Simulation studies indicate that four of these indicators (CAIC, BIC, ABIC, and BLRT) are particularly effective (Henson, Reise, \& Kim, 2007; Nylund, Asparouhov, \& Muthén, 2007; Peugh \& Fan, 2013; Tein, Coxe, \& Cham, 2013; Tofighi \& Enders, 2008), while the AIC and LMR/ALMR should not be used in the class enumeration process as they respectively tend to over- and under-extract incorrect number of profiles (Diallo et al., 2016, 2017; Henson et al., 2007; Nylund et al., 2007; Peugh \& Fan, 2013; Tofighi \& Enders, 2008). These indicators will only be reported to ensure a complete disclosure, but will not be used to select the optimal number of profiles. It should be noted that these tests remain heavily influenced by sample size (Marsh et al., 2009), so that with sufficiently large samples, they may keep on suggesting the addition of profiles without reaching a minimum. In this situation, the point at which these indicators appear to reach a plateau can be used to suggest the optimal solution (Morin, Maïano et al., 2011). Finally, the entropy indicates the precision with which the cases are classified into the various profiles (varying from 0 to 1 ), but should not be used to determine the optimal number of profiles (Lubke \& Muthén, 2007).

\section{Predictors and Outcomes of Profile Membership}

Multinomial logistic regressions were conducted to test the relations between the predictors and profile membership. In addition to analyses involving these predictors, associations between the profiles and a series of outcomes were also assessed using a model-based approach proposed by Lanza, Tan, and Bray (2013) and implemented through the Auxiliary (DCON) function (Asparouhov \& Muthén, 2014). Predictors and outcomes were incorporated to the model as factor scores saved from a preliminary measurement model reported in the online supplements. Correlations among all variables used in this study are reported in Table S6 of the online supplements.

\section{Latent Profile Solutions}

\section{Results}

The fit indices of the LPAs estimated from bifactor-ESEM factor scores are reported in Table 1. All information criteria kept on suggesting the addition of profiles up to the seven-profile solution, whereas the BLRT supported the five-profile solution. However, the elbow plot associated with these solutions (reported in Figure S1 of the online supplements) revealed that the decrease in the value of these information criteria reached a plateau after the three-profile solution. Based on these observations, we carefully examined solutions including three to five profiles. This examination showed that all solutions were fully proper statistically. Furthermore, this examination revealed that moving from three to four profiles resulted in the addition of a meaningfully different profile to the solution (i.e., corresponding to Profile 1 illustrated in Figure 1), whereas adding a fifth profile simply resulted into the arbitrary division of one of the existing profiles into two smaller profiles (the smallest corresponding to approximately 5\% of the sample) presenting a very similar shape. The four-profile solution, illustrated in Figure 1, was thus retained. Parameter estimates from this solution are reported in Table S7 of the online supplements.

This solution based on bifactor-ESEM factor scores resulted in profiles presenting clear shape differences. This observation is aligned with Morin, Boudrias et al.'s $(2016,2017)$ observation that relying on bifactor factor scores helps to extract profiles differing both in terms of the global construct underlying participants' ratings across all items (here reflecting their global level of job engagement), but also based on their specific levels of physical, emotional, and cognitive job engagement left unexplained by this global construct. The results also revealed a high level of classification accuracy of participants into their most likely profile (see Table S8 of the online supplements), ranging from $70.1 \%$ to $99.6 \%$ across profiles.

When interpreting this solution, a first noteworthy observation lies in the identification of a Moderately Engaged profile (Profile 4), representing $47.73 \%$ of the employees. The label Moderately Engaged was retained to reflect the fact that this profile reflected a subpopulation of employees whose global levels of 
job engagement was close to the sample average, and coupled with specific levels of physical, emotional, and cognitive job engagement similarly close to the sample average. The identification of such a large profile suggested that most employees tended to display well-balanced and moderate (i.e., average) levels of job engagement across all three dimensions. In contrast, the remaining profiles were characterized not only by low (Profile 1) or high (Profiles 2 and 3) global levels of job engagement, but also by some degree of imbalance between the specific job engagement components. Thus, members of Profile 1 were characterized by moderately low levels of emotional and cognitive job engagement, but by moderately high levels of physical job engagement. This Globally Disengaged profile characterized $12.50 \%$ of the employees. In contrast, members of Profile 2 were characterized by average levels of physical job engagement, but by moderately high levels of emotional and cognitive job engagement. This Globally Engaged profile characterized 16.29\% of the employees. Finally, members of Profile 3 were characterized by average levels of physical and cognitive job engagement, but by moderately low levels of emotional job engagement. This Globally but not Emotionally Engaged profile characterized $23.49 \%$ of the employees. In line with the observation that the specific factor reflecting physical job engagement, it is noteworthy that this specific factor was also the one showing the smallest differences across profiles.

Associations with Outcomes. Associations between outcomes and profile membership are reported in Table 2. These analyses revealed that the highest levels of affective commitment were associated with the Globally Engaged (2) profile, followed by the Globally but not Emotionally Engaged (3) and Moderately Engaged (4) profiles which could not be differentiated from one another, and finally by the Globally Disengaged (1) profile. The lowest levels of normative commitment were associated with the Globally Disengaged (1) profile, followed by the Globally but not Emotionally Engaged (3) profile, and finally by the Globally Engaged (2) and Moderately Engaged (4) profiles which could not be differentiated from one another. The Globally Disengaged (1) and Globally but not Emotionally Engaged (3) profiles were associated with higher levels of emotional exhaustion than the Globally Engaged (2) and Moderately Engaged (4) profiles. Finally, the Globally Engaged (2) profile was associated with lower levels of illbeing relative to all other profiles, which could not be differentiated from one another.

Predictors of Profile Membership. Associations between predictors and profile membership are reported in Table 3. Task variety predicted a decreased likelihood of membership in the Globally Disengaged (1) profile relative to the Globally Engaged (2) and Moderately Engaged (4) profiles, and an increased likelihood of membership in the Globally Engaged (2) profile relative to the Globally but not Emotionally Engaged (3) and Moderately Engaged (4) profiles. Feedback and being a female predicted a decreased likelihood of membership in the Globally Disengaged (1) profile relative to the three other profiles. Working full time similarly predicted a decreased likelihood of membership in the Globally Disengaged (1) profile relative to the Globally but not Emotionally Engaged (3) profile, whereas tenure predicted an increased likelihood of membership in the Globally but not Emotionally Engaged (3) profile relative to the Moderately Engaged (4) profile. Finally, work autonomy, task significance, task identity, and education levels appeared to be unrelated to the likelihood of membership into any of the profiles.

\section{Discussion}

Despite the recognition of the interrelated nature of the physical, emotional, and cognitive facets of job engagement (e.g., Shuck et al., 2017), the ways these components are combined among specific subpopulations, or profiles, of employees have never been investigated in the work context. Yet, a recent study conducted by Gillet, Caesens et al. (2019) on the related construct of work engagement supported a bifactor representation of employees' work engagement, providing a way to obtain a direct estimate of global levels of work engagement properly disaggregated form the specificity uniquely associated with the vigor, dedication, and absorption facets. They further showed that this improved representation allowed them to achieve a more differentiated representation of the work engagement profiles most commonly observed among employees in comparison with results previously reported by Simbula et al. (2013) on the basis of a more traditional representation of work engagement ignoring this dual global/specific nature. The present study was designed to assess whether similar conclusions would apply to the job engagement construct. In addition, the present study was also designed to expand upon the results from these prior studies (Gillet, Caesens et al., 2019; Simbula et al., 2013) by investigating the role of demographic 
(gender, education, working time, and organizational tenure) and job (work autonomy, task variety, task significance, task identity, and feedback) characteristics in the prediction of profile membership, and by documenting the implications of these profiles in terms of attitudes (affective and normative commitment) and psychological health (emotional exhaustion and ill-being).

\section{Employees' Job Engagement Profiles}

Results revealed the presence of four distinct job engagement profiles among the present sample of French employees: (1) Globally Disengaged; (2) Globally Engaged; (3) Globally but not Emotionally Engaged; and (4) Moderately Engaged. These profiles emphasize the importance of adopting a finergrained representation of job engagement by simultaneously considering the global levels of job engagement and the specific nature of the physical, emotional, and cognitive facets of job engagement over and above this global level of job engagement, reflecting the extent to which the level of each specific facet deviates from that global level for specific employees. In particular, results showed that the profiles characterized by high (the Globally Engaged and Globally but not Emotionally Engaged profiles) or low (the Globally Disengaged profile) global levels of job engagement tended to present a more imbalanced configuration where specific levels of job engagement generally tended to deviate from the sample average. In contrast, the Moderately Engaged profile, characterized by moderate global levels of job engagement, presented a more balanced configuration where specific levels of job engagement were aligned with one another and with the sample average.

When considering these results, it is important to keep in mind that profiles were identified using four indicators respectively reflecting global levels of job engagement (a global factor score computed from the variance shared across all physical, emotional, and cognitive engagement items), as well as specific levels of physical, emotional, and cognitive engagement (specific factors reflecting what is unique to physical, emotional, or cognitive engagement ratings, once the variance explained by the global factor is taken into account). Yet, although the preliminary analyses from which these factor scores were generated resulted in the estimation of well-defined global, specific emotional, and specific cognitive engagement factors, the physical engagement factor was more weakly defined. This result implies that, in the present sample, ratings on the six items used to evaluate physical engagement provided a much better reflection of employees' global levels of job engagement than of the specific facet of physical engagement. In plain language, this means that ratings of physical engagement mainly serve to define global levels of job engagement in the present sample, with limited evidence of discrepancies between individual levels of physical engagement and of global engagement. This result could explain why the physical S-factor was the one showing the least pronounced deviations from the sample average across most of the identified profiles. This result is also consistent with findings from prior studies showing that job engagement has stronger effects on discretionary components of job performance than on required components (Friedman, Carmeli, \& Dutton, 2018). Indeed, it is not uncommon for employees to find enough physical energy to do their jobs simply because it is necessary to keep their jobs, whether they are engaged or disengaged. They do what they have to do to keep their job and get paid. Conversely, finding the energy to do discretionary acts, or managing to be emotionally and cognitively engaged requires a different level of connection with the work, going beyond simply showing up to work. It would be interesting for future investigations relying on bifactor models to assess more extensively the situations, occupations, and professional contexts which may lead to more or less frequent degrees of misalignment between employees' global ratings of job engagement and their specific ratings of physical, emotional, and cognitive engagement.

Globally Disengaged Employees. When considering the identified profiles more specifically, members of Profile 1 (Globally Disengaged profile) were characterized by low global levels of job engagement and experienced misaligned low levels of emotional and cognitive job engagement relative to their global levels of job engagement. This Globally Disengaged profile shares some similarities with the Ill-Adjusted Extrinsically Driven profile identified by Morin, Boudrias et al. (2017) and characterized by low levels of global well-being, interpersonal fit, and competence. Morin, Boudrias et al. (2016) also identified a similar profile characterized by low global levels of psychological health, irritability, and anxiety/depression. In the present study, these employees were also found to present the most maladaptive functioning (i.e., the lowest levels of affective and normative commitment, and the highest levels of ill- 
being and emotional exhaustion). These results are aligned with prior research showing that employees characterized by low levels of job engagement tend to withhold their physical, cognitive, and emotional energies, and to display a work pattern that might appear to be passive, robotic, and detached (Kahn, 1990), thus leading them to experience adverse consequences (e.g., Rich et al., 2010). Our results also showed that female employees were less likely to correspond to this Globally Disengaged profile. This gender difference is consistent with prior research demonstrating that women exhibited greater job involvement than men (Lorence, 1987) and indicating that women are more committed to work roles (Angle \& Perry, 1981). This result suggests that women may need to invest themselves more in their work than men do in order to survive in the workplace (Lee \& Eissenstat, 2018). It would be interesting for future research to assess the role of different organizational practices possibly at play in determining this gender difference, such as, for example, family policies or gender-differentiated treatment.

Globally Engaged Employees. In contrast, members of Profile 2 (Globally Engaged profile) were characterized by high global levels of job engagement and experienced even higher levels of emotional and cognitive job engagement relative to their global levels of job engagement. This Globally Engaged profile is similar to the Engaged yet Distanced one identified by Gillet, Caesens et al. (2019) and characterized by moderately high levels of global work engagement, vigor, and dedication. Globally Engaged employees also presented the most desirable outcome levels (e.g., higher levels of affective and normative commitment, and lower levels of ill-being and emotional exhaustion). Thus, as far as these first two profiles (Globally Disengaged and Globally Engaged) are considered, our results showed associations that mainly matched our expectations and previous research results (e.g., Gillet, Caesens et al., 2019; Park et al., 2017; Shuck \& Reio Jr., 2014; Zhong et al., 2016), supporting the role of job engagement in the prediction of a variety of outcomes.

Globally but not Emotionally Engaged Employees. Members of Profile 3 (Globally but not Emotionally Engaged) were characterized by high global levels of job engagement and experienced misaligned low levels of emotional job engagement relative to their global levels of job engagement. Morin, Boudrias et al. (2016) also identified a profile (Adapted) characterized by high levels of global psychological health, and relatively low levels on the specific indicators of psychological distress and wellbeing. More experienced employees, as well as full time employees, were more likely to correspond to this profile, and thus to be more connected, attentive, focused, and physically involved in their role performance (Kahn, 1990) but also more able to emotionally disconnect from it. With tenure and work time, workers accumulate more task-related knowledge and skills and become more likely to assume a central role in the organization, thus leading to better person-organization fit and higher levels of job engagement (Bal, De Cooman, \& Mol, 2013; Ng \& Feldman, 2010; Uppal, 2017; Veltrop, Molleman, Hooghiemstra, \& van Ees, 2018). However, members of this profile also presented levels of emotional exhaustion and ill-being similar to those observed in the Globally Disengaged profile. This result suggests that experiencing misaligned low levels of emotional job engagement relative to one's global levels of job engagement appears to carry as much risk in terms of ill-being and emotional exhaustion as experiencing globally low levels of job engagement. There might thus be limits to the benefits of high global levels of job engagement, particularly when not accompanied by matching levels of emotional engagement. Conversely, low levels of emotional job engagement thus appear particularly harmful, even for employees' with otherwise high global levels of job engagement.

Moderately Engaged Employees. Finally, the identification of a large (47.73\%) Moderately Engaged profile suggests that, for almost half of the sample, global levels of job engagement remained satisfactory and well-aligned across all three components. This result is concordant with prior investigations which also identified the presence of a dominant profile similarly characterized by moderate levels of work engagement (Gillet, Caesens et al., 2019), well-being (Morin, Boudrias et al., 2016, 2017) or need satisfaction (Gillet, Morin, Choisay, \& Fouquereau, 2019). Interestingly, the levels of affective commitment and ill-being observed in this profile were impossible to distinguish from those observed in the Globally but not Emotionally Engaged one, while this profile did present higher levels of normative commitment and lower levels of emotional exhaustion, reinforcing the idea that low emotional engagement reduces the positive effects of global job engagement. Likewise, levels of normative 
commitment and emotional exhaustion observed in this profile were impossible to distinguish from those observed in the Globally Engaged profile, although both of these profiles displayed more desirable levels on these outcomes than the remaining profiles. Matching previous results related to the work engagement construct (e.g., Gilet, Morin et al., 2019), these results suggests that employees who experienced a balanced level of job engagement tended to report similar levels of normative commitment and emotional exhaustion than other workers presenting higher global levels of job engagement but a more unbalanced profile. This level of balance among the job engagement components could be taken to reflect a more appropriate allocation of resources across different work facets, which could help to reduce stress and conflict, and ultimately lead to positive outcomes.

\section{Determinants of Profile Membership}

Our results revealed widespread associations between task variety and feedback and the likelihood of profile membership. Thus, task variety predicted a decreased likelihood of membership in the Globally Disengaged profile relative to the Globally Engaged and Moderately Engaged profiles, and an increased likelihood of membership in the Globally Engaged profile relative to the Globally but not Emotionally Engaged and Moderately Engaged profiles. Feedback also predicted a decreased likelihood of membership in the Globally Disengaged profile relative to the three other profiles. In other words, task variety and feedback predicted membership into profiles characterized by higher levels of global job engagement. This result is consistent with the literature on job characteristics that depicts task variety and feedback as positive job characteristics (Hackman \& Oldham, 1976) due to their desirable consequences on individual functioning (e.g., Morgeson \& Humphrey, 2006). In contrast, work autonomy, task significance, and task identity appeared to be unrelated to the likelihood of membership into any of the profiles. This result differs from our expectations anchored in previous variable-centered research (Morgeson \& Humphrey, 2006), which could possibly be explained by our adoption of a multivariate perspective in which these various job characteristics were simultaneously considered. This approach allowed us to identify the most potent predictors of profile membership once the variance shared among these various job characteristics was considered. Indeed, as shown in Table S6 of the online supplements, these work characteristics were found to be moderately correlated with one another $(r=.235$ to $.620 ; M=.455)$ and to present similar univariate associations with the job engagement facets considered individually. More generally, our findings further encourage researchers to look into how various job characteristics - rather than to focus on global measures of job enrichment (Hackman \& Oldham, 1976) - uniquely contribute to employees' job engagement profiles.

\section{Practical Implications for Intervention, Research, and Assessment}

In intervention terms, our results emphasizes that organizations and managers could gain by adopting practices seeking to promote higher levels of job engagement among employees, and to nurture engagement for employees displaying low engagement levels. Our results also show that managers ought to be particularly attentive to workers exposed to low levels of task variety and having access to limited amount of feedback. Indeed, these individuals are subjected to the lowest levels of global job engagement which expose them to higher risks of maladaptive functioning (e.g., low affective and normative commitment, ill-being, exhaustion). Therefore, changes in a work organization designed to increase the level of task variety sustainably, and which makes it easier for employees to access relevant feedback, might increase job engagement in the long run. In line with previous investigations on job enrichment interventions (Parker, 1998), the effects of an increase in task variety might be most favorable when workers report having the information they require, as well as the opportunity to obtain the skills needed to complete new work tasks. However, because increasing skill variety is not always feasible, intervening at the level of task sequencing might be a more realistic approach (Derfler-Rozin, Moore, \& Staats, 2016). Employees often have multiple tasks that may not have a required sequence, but organizations may be able to structure them so that they accrue the benefits identified in this research (i.e., higher levels of global job engagement). Our results also suggest that a possible way for nurturing higher levels of global job engagement is to design workers' activities in such a way that they could receive constant feedback about the appropriateness and effectiveness of their task performance. Organizations with limited opportunities to increase task variety or feedback might profit from interventions such as promoting 
psychological need satisfaction and autonomous motivation in the workplace (Gillet, Morin et al., 2017, 2019). Among ways to do this, top management could reduce employee work overload and promote justice and fairness in terms of policy implementation and rewards distribution (Gagné \& Deci, 2005).

From a research perspective, our results highlight that failure to consider the possibility that job engagement ratings may simultaneously tap into one global and three specific job engagement factors is likely to erroneously lead to the conclusion that physical, emotional, and cognitive job engagement simply reflect relatively independent constructs with comparable effects. Indeed, these comparable effects would mainly reflect the underlying effects of employees' global levels of job engagement, and serve to hide the possible complementary effects between the S-factors. Ignoring this form of multidimensionality is thus likely to lead to a biased view of the validity of the job engagement construct and of the reality under study. For applied researchers interested in job engagement, this means that the ability to obtain a clear and valid estimate of the way job engagement ratings related to other constructs of interest is likely to be biased, and more importantly to lead to biased recommendations for practice.

Finally, from an assessment perspective, in order to avoid job engagement estimates reflecting a confusing mixture of global and specific variance likely to be tainted by multicollinearity, researchers and practitioners are thus invited to consider adopting a bifactor-ESEM representation of job engagement ratings in their own work. This recommendation strongly advocates a latent variable approach to research. Yet, this recommendation is not as easy to transpose to the professional context where practitioners and organizations still need to be able to score job engagement questionnaires. In these contexts, automated scoring procedures relying on calculations similar to those involved in the generation of the factor scores used in the present study will need to be developed. As noted by Perreira et al. (2018), the Mplus statistical package could be used in such a manner on the basis of the parameter estimates obtained in the present study. A key advantage of this approach is that the resulting scores will be directly estimated in standardized units, and thus interpretable as a function of the sample mean and standard deviation, just like normed scores, making it easier to identify the most likely profile membership of employees. Yet, as with any norm, this consideration reinforces the importance for future research to rely on more representative samples prior to the development of any practically-useful scoring procedure.

\section{Limitations and Directions for Future Research}

Even though this study represent the first systematic attempt at investigating the nature, predictors, and outcomes of employees' job engagement profiles, it presents some limitations worth noting. First, we relied on self-report measures, which may have been impacted by social desirability and self-report biases. Future research should consider relying on more objective indicators of individual and organizational functioning (e.g., job performance, turnover) together with informant-reported (e.g., manager) measures of job characteristics. Second, the present study relied on a convenience sample of French workers, which cannot be considered to be representative of the population of French workers. Additional person-centered research should thus be conducted to assess the generalizability of the identified profiles and of their associations with predictors and outcomes, across distinct samples of employees (e.g., office workers, teleworkers, managers), and in different cultures and countries (Morin, Meyer et al., 2016). Such evidence of generalizability would help to demonstrate the robustness of our findings and the value of implementing intervention strategies based on such person-centered results.

Third, in line with Meyer and Morin's (2016) recommendations, we examined covariates defined a priori as either predictors (i.e., gender, age, education, working time, organizational tenure, work autonomy, task variety, task significance, task identity, and feedback) or outcomes (i.e., affective and normative commitment, emotional exhaustion, and ill-being) on the basis of a theoretical rationale drawn from prior research (e.g., Rich et al., 2010). Although our analytical approach made it possible to rule out possible effects of predictors on profile membership, our study design and the limitations inherent to our analytical method did not allow us to assess reversed causality, reciprocal influence, or spurious associations, nor the possible role of profile membership in the prediction of changes in outcome levels. Therefore, future longitudinal research would gain from examining more systematically the direction of the associations among predictors, outcomes, and profiles within the context of a longitudinal research design. Indeed, longitudinal research makes it possible to address the joint issues of within-person and 
within-sample profile stability (Gillet, Morin, \& Reeve, 2017; Kam, Morin, Meyer, \& Topolnytsky, 2016). More precisely, it would be interesting to examine whether the engagement profiles identified in the current study change in terms of number, structure, variability, size, and outcomes across time (withinsample stability) and whether membership into the different job engagement profiles remain stable (within-person stability). Future research may also consider the possible mechanisms at play in explaining these potential profile transitions. Finally, we only looked into the role of demographic and job characteristics as determinants of employees' job engagement profiles. Yet, it would be worthwhile for future research to investigate other determinants inherent to the work environment (e.g., managerial behaviors) or individual orientations (i.e., job crafting, perfectionism). Likewise, our results revealed that the implications of profile membership differed across outcomes. This observation thus reinforces the importance for future research to consider a broader range of desirable (e.g., organizational citizenship behaviors, job performance) and undesirable (e.g., turnover, work-family conflict) outcomes in order to better understand the mechanisms at play in explaining these differential effects.

\section{Conclusion}

The present study extends the research literature on employees' job engagement in several directions. First, it emphasizes the importance of simultaneously considering the global levels of job engagement and the specific nature of the physical, emotional, and cognitive facets of job engagement over and above this global level of job engagement. Second, it revealed that employees job engagement generally follows four distinct configurations, corresponding to a Globally Engaged, a Globally Disengaged, a Globally but not Emotionally Engaged, and a Moderately Engaged profile. In doing so, it also revealed that high or low global levels of job engagement tended to be characterized by greater levels of imbalance across engagement components when compared to moderate global levels of job engagement. Third, the Globally Disengaged profile was associated the most detrimental outcomes, while the Globally Engaged profile was associated with the most desirable outcomes. However, negative consequences appeared to be associated with the display of low imbalanced levels of emotional engagement even among globally engaged employees. Thus, these results suggested that balance among global levels of job engagement, and specific levels of physical, emotional, and cognitive job engagement may lead to positive outcomes. Finally, our results showed that tenure, working time, gender, task variety, and feedback were all significantly associated with profile membership. More particularly, task variety and feedback were both found to predict membership into more desirable profiles characterized by higher levels of global job engagement.

\section{References}

Angle, H.L., \& Perry, J.L. (1981). An empirical assessment of organizational commitment and organizational effectiveness. Administrative Science Quarterly, 26, 1-14.

Ashforth, B.E., \& Humphrey, R.H. (1995). Emotion in the workplace: A reappraisal. Human Relations, 48, 97-125.

Asparouhov, T., \& Muthén, B. (2014). Auxiliary variables in mixture modeling: Three-step approaches using Mplus. Structural Equation Modeling, 21, 329-341.

Asparouhov, T., Muthén, B., \& Morin, A.J.S. (2015). Bayesian structural equation modeling with crossloadings and residual covariances. Journal of Management, 41, 1561-1577.

Bakker, A.B., Demerouti, E., \& Sanz-Vergel, A.I. (2014). Burnout and work engagement: The JD-R approach. Annual Review of Organizational Psychology and Organizational Behavior, 1, 389-411.

Bal, P.M., De Cooman, R., \& Mol, S.T. (2013). Dynamics of psychological contracts with work engagement and turnover intention: The influence of organizational tenure. European Journal of Work and Organizational Psychology, 22, 107-122.

Bigot, L., Fouquereau, E., Lafrenière, M.-A., Gimenes, G., Becker, C., \& Gillet, N. (2014). Analyse préliminaire des qualités psychométriques d'une version française du Work Design Questionnaire. Psychologie du Travail et des Organisations, 20, 203-232.

Brauchli, R., Schaufeli, W.B., Jenny, G.J., Füllemann, D., \& Bauer, G.F. (2013). Disentangling stability and change in job resources, job demands, and employee well-being-A three-wave study on the JobDemands Resources model. Journal of Vocational Behavior, 83, 117-129. 
Byrne, Z.S., Peters, J.M., \& Weston, J.W. (2016). The struggle with employee engagement: Measures and construct clarification using five samples. Journal of Applied Psychology, 101, 1201-1227.

Caesens, G., Stinglhamber, F., \& Marmier, V. (2016). The curvilinear effect of work engagement on employees' turnover intentions. International Journal of Psychology, 51, 150-155.

Chen, F.F., West, S.G., \& Sousa, K.H. (2006). A comparison of bifactor and second-order models of quality of life. Multivariate Behavioral Research, 41, 189-225.

Christian, M.S., Garza, A.S., \& Slaughter, J.E. (2011). Work engagement: A quantitative review and test of its relations with task and contextual performance. Personnel Psychology, 64, 89-136.

Crawford, E.R., LePine, J.A., \& Rich, B.L. (2010). Linking job demands and resources to employee engagement and burnout: A theoretical extension and meta-analytic test. Journal of Applied Psychology, 95, 834-848.

Demerouti, E., Bakker, A.B., \& Leiter, M. (2014). Burnout and job performance: The moderating role of selection, optimization, and compensation strategies. Journal of Occupational Health Psychology, 19, 96-107.

Derfler-Rozin, R., Moore, C., \& Staats, B.R. (2016). Reducing organizational rule breaking through task variety: How task design supports deliberative thinking. Organization Science, 27, 1361-1379.

Diallo, T.M.O, Morin, A.J.S., \& Lu, H. (2016). Impact of misspecifications of the latent variance-covariance and residual matrices on the class enumeration accuracy of growth mixture models. Structural Equation Modeling, 23, 507-531.

Diallo, T.M.O, Morin, A.J.S., \& Lu, H. (2017). The impact of total and partial inclusion or exclusion of active and inactive time invariant covariates in growth mixture models. Psychological Methods, 22, 166-190.

Edwards, J.R. (2009). Latent variable modeling in congruence research: Current problems and future directions. Organizational Research Methods, 12, 34-62.

Enders, C. (2010). Applied missing data analysis. New York, NY: Guilford.

Finney, S.J., \& DiStefano, C. (2013). Non-normal and categorical data in structural equation modeling. In G.R. Hancock \& R.O. Mueller (Eds), Structural equation modeling: A second course (2 ${ }^{\text {nd }}$ ed., pp. 439492). Greenwich, CO: IAP.

Friedman, A., Carmeli, A., \& Dutton, J.E. (2018). When does respectful engagement with one's supervisor foster help-seeking behaviors and performance? Journal of Vocational Behavior, 104, 184-198.

Gagné, M., \& Deci, E.L. (2005). Self-determination theory and work motivation. Journal of Organizational Behavior, 26, 331-362.

Gignac, G.E. (2016). The higher-order model imposes a proportionality constraint: That is why the bifactor model tends to fit better. Intelligence, 55, 57-68.

Gillet, N., Caesens, G., Morin, A.J.S, \& Stinglhamber, F. (2019). Complementary variable- and personcentred approaches to the dimensionality of work engagement: A longitudinal investigation. European Journal of Work and Organizational Psychology, 28, 239-258.

Gillet, N., Morin, A.J.S., \& Reeve, J. (2017). Stability, change, and implications of students' motivation profiles: A latent transition analysis. Contemporary Educational Psychology, 51, 222-239.

Gillet, N., Morin, A.J.S., Choisay, F. \& Fouquereau, E (2019). A person-centered representation of basic need satisfaction balance at work. Journal of Personnel Psychology, 18, 113-128.

Hackman, J.R., \& Oldham, G.R. (1976). Motivation through the design of work: Test of a theory. Organizational Behavior \& Human Performance, 16, 250-279.

Halbesleben, J.R.B. (2010). A meta-analysis of work engagement: Relationships with burnout, demands, resources, and consequences. In A.B. Bakker \& M.P. Leiter (Eds.), Work engagement: A handbook of essential theory and research (pp. 102-117). New York, NY: Psychology Press.

Hambleton, R.K. (2005). Applications of item response theory to improve health outcomes assessment: Developing item banks, linking instruments, and computer-adaptive testing. In J. Lipscomb, C.C. Gotay, \& C. Snyder (Eds.), Outcomes assessment in cancer: Measures, methods, and applications (pp. 445-464). New York, NY: Cambridge University Press.

Haynie, J.J., Mossholder, K.W., \& Harris, S.G. (2016). Justice and job engagement: The role of senior 
management trust. Journal of Organizational Behavior, 37, 889-910.

Henson, J.M., Reise, S.P., \& Kim, K.H. (2007). Detecting mixtures from structural model differences using latent variable mixture modeling: A comparison of relative model fit statistics. Structural Equation Modeling, 14, 202-226.

Hipp, J.R., \& Bauer, D.J. (2006). Local solutions in the estimation of growth mixture models. Psychological Methods, 11, 36-53.

Huang, C.-S., \& Simha, A. (2018). The mediating role of burnout in the relationships between perceived fit, leader-member exchange, psychological illness, and job performance. International Journal of Stress Management, 25, 26-42.

Innanen, H., Tolvanen, A., \& Salmela-Aro, K. (2014). Burnout, work engagement and workaholism among highly educated employees. Burnout Research, 1, 38-49.

Jennrich, R.I., \& Bentler, P.M. (2011). Exploratory bi-factor analysis. Psychometrika, 76, 537-549.

Kahn, W.A. (1990). Psychological conditions of personal engagement and disengagement at work. Academy of Management Journal, 33, 692-724.

Kam, C., Morin, A.J.S., Meyer, J.P., \& Topolnytsky, L. (2016). Are commitment profiles stable and predictable? A latent transition analysis. Journal of Management, 42, 1462-1490.

Knoll, M., \& Redman, T. (2016). Does the presence of voice imply the absence of silence? The necessity to consider employees' affective attachment and job engagement. Human Resource Management, 55, 829-844.

Lanza S.T., Tan X., \& Bray B.C. (2013). Latent class analysis with distal outcomes: A flexible modelbased approach. Structural Equation Modeling, 20, 1-26.

Lapointe, É., Vandenberghe, C., \& Boudrias, J.-S. (2013). Psychological contract breach, affective commitment to organization and supervisor, and newcomer adjustment: A three-wave moderated mediation model. Journal of Vocational Behavior, 83, 528-538.

Lee, Y., \& Eissenstat, S.J. (2018). An application of work engagement in the job demands-resources model to career development: Assessing gender differences. Human Resource Development Quarterly, 29, 143-161.

Lo, Y., Mendell, N., \& Rubin, D. (2001). Testing the number of components in a normal mixture. Biometrika, $88,767-778$.

Lorence, J. (1987). A test of "gender" and "job" models of sex differences in job involvement. Social Forces, 66, 121-142.

Lubke, G.H., \& Muthén, B.O. (2005). Investigating population heterogeneity with factor mixture models. Psychological Methods, 10, 21-39.

Macey, W.H., \& Schneider, B. (2008). The meaning of employee engagement. Industrial and Organizational Psychology, 1, 3-30.

Mäkikangas, A., \& Kinnunen, U. (2016). The person-oriented approach to burnout: A systematic review. Burnout Research, 3, 11-23.

Mäkikangas, A., Hyvönen, K., \& Feldt, T. (2017). The energy and identification continua of burnout and work engagement: Developmental profiles over eight years. Burnout Research, 5, 44-54.

Mäkikangas, A., Kinnunen, U., Feldt, T., \& Schaufeli, W.B. (2016). The longitudinal development of employee well-being: A systematic review. Work \& Stress, 30, 46-70.

Mäkikangas, A., Rantanen, J., Bakker, A.B., Kinnunen, M.-L., Pulkkinen, L., \& Kokko, K. (2015). The circumplex model of occupational well-being: Its relation with personality. Journal for PersonOriented Research, 1, 115-129.

Marchand, C., \& Vandenberghe, C. (2016). Perceived organizational support, emotional exhaustion, turnover: The moderating role of negative affectivity. International Journal of Stress Management, 23, 350-375.

Marinova, S.V., Peng, C., Lorinkova, N., Van Dyne, L., \& Chiaburu, D. (2015). Change-oriented behavior: A meta-analysis of individual and job design predictors. Journal of Vocational Behavior, 88, 104-120.

Marsh, H.W., \& Hau, K.-T. (2007). Applications of latent-variable models in educational psychology: The need for methodological-substantive synergies. Contemporary Educational Psychology, 32, 151-171. 
Marsh, H.W., Lüdtke, O., Trautwein, U., \& Morin, A.J.S. (2009). Classical latent profile analysis of academic self-concept dimensions: Synergy of person- and variable-centered approaches to theoretical models of self-concept. Structural Equation Modeling, 16, 191-225.

May, D.R., Gilson, R.L., \& Harter, L.M. (2004). The psychological conditions of meaningfulness, safety and availability and the engagement of the human spirit at work. Journal of Occupational and Organizational Psychology, 77, 11-37.

McLachlan, G., \& Peel, D. (2000). Finite mixture models. New York, NY: Wiley.

Meyer, J.P., \& Morin, A.J.S. (2016). A person-centered approach to commitment research: Theory, research, and methodology. Journal of Organizational Behavior, 37, 584-612.

Meyer, J.P., Allen, N.J., \& Smith, C.A. (1993). Commitment to organizations and occupations: Extension and test of a three-component conceptualization. Journal of Applied Psychology, 78, 538-551.

Meyer, J. P., Stanley, D.J., Herscovitch, L., \& Topolnytsky, L. (2002). Affective, continuance and normative commitment to the organization: A meta-analysis of antecedents, correlates, and consequences. Journal of Vocational Behavior, 61, 20-52.

Morgeson, F.P., Humphrey, S.E. (2006). The Work Design Questionnaire (WDQ): Developing and validating a comprehensive measure for assessing job design and the nature of work. Journal of Applied Psychology, 91, 1321-1339.

Morin, A.J.S. (2016). Person-centered research strategies in commitment research. In J.P. Meyer (Ed.), The handbook of employee commitment (pp. 490-508). Cheltenham, UK: Edward Elgar.

Morin, A.J.S., Arens, A.K., \& Marsh, H. (2016). A bifactor exploratory structural equation modeling framework for the identification of distinct sources of construct-relevant psychometric multidimensionality. Structural Equation Modeling, 23, 116-139.

Morin, A.J.S., Boudrias, J.-S., Marsh, H.W., Madore, I., \& Desrumaux, P. (2016). Further reflections on disentengling shape and level effects in person-centered analyses: An illustration exploring the dimensionality of psychological health. Structural Equation Modeling, 23, 438-454.

Morin, A.J.S., Boudrias, J.-S., Marsh, H.W., McInerney, D.M., Dagenais-Desmarais, V., Madore, I., \& Litalien, D. (2017). Complementary variable- and person-centered approaches to the dimensionality of psychometric constructs: Application to psychological wellbeing at work. Journal of Business and Psychology, 32, 395-419.

Morin, A.J.S., Maïano, C., Nagengast, B., Marsh, H.W., Morizot, J., \& Janosz, M. (2011). Growth mixture modeling of adolescents trajectories of anxiety: The impact of untested invariance assumptions on substantive interpretations. Structural Equation Modeling, 18, 613-648.

Morin, A.J.S., Meyer, J.P., Creusier, J., \& Biétry, F. (2016). Multiple-group analysis of similarity in latent profile solutions. Organizational Research Methods, 19, 231-254.

Morin, A.J.S., Morizot, J., Boudrias, J.-S., \& Madore, I. (2011). A multifoci person-centered perspective on workplace affective commitment: A latent profile/factor mixture analysis. Organizational Research Methods, 14, 58-90.

Morin, A.J.S., Vandenberghe, C., Turmel, M.-J., Madore, I., \& Maïano, C. (2013). Probing into commitment's nonlinear relationships to work outcomes. Journal of Managerial Psychology, 28, 202-223.

Morin, A.J.S., \& Wang, J.C.K. (2016). A gentle introduction to mixture modeling using physical fitness data. In N. Ntoumanis \& N. Myers (Eds.), An introduction to intermediate and advanced statistical analyses for sport and exercise scientists (pp. 183-210). London, UK: Wiley.

Muthén, B.O. (2003). Statistical and substantive checking in growth mixture modeling: Comment on Bauer and Curran (2003). Psychological Methods, 8, 369-377.

Muthén, L.K., \& Muthén, B. (2017). Mplus user's guide. Los Angeles, CA: Muthén \& Muthén.

Newman, D.A., \& Harrison, D.A. (2008). Been there, bottled that: Are state and behavioral work engagement new and useful construct "wines"? Industrial and Organizational Psychology, 1, 31-35.

Ng, T.W.H., \& Feldman, D.C. (2010). Organizational tenure and job performance. Journal of Management, 36, 1220-1250.

Nimon, K., Shuck, B., \& Zigarmi, D. (2016). Construct overlap between employee engagement and job satisfaction: A function of semantic equivalence? Journal of Happiness Studies, 17, 1149-1171. 
Nylund, K.L., Asparouhov, T., \& Muthén, B. (2007). Deciding on the number of classes in latent class analysis and growth mixture modeling. Structural Equation Modeling, 14, 535-569.

Park, J.G., Kim, J.S., Yoon, S.W., \& Joo, B.-K. (2017). The effects of empowering leadership on psychological well-being and job engagement: The mediating role of psychological capital. Leadership \& Organization Development Journal, 38, 350-367.

Parker, S.K. (1998). Enhancing role breadth self-efficacy: The roles of job enrichment and other organizational interventions. Journal of Applied Psychology, 83, 835-852.

Perreira, T.A., Morin, A.J.S., Hebert, M., Gillet, N., Houle, S.A., \& Berta, W. (2018). The short form of the Workplace Affective Commitment Multidimensional Questionnaire (WACMQ-S): A bifactor-ESEM approach among healthcare professionals. Journal of Vocational Behavior, 106, 62-83.

Peugh, J., \& Fan, X. (2013). Modeling unobserved heterogeneity using latent profile analysis: A Monte Carlo simulation. Structural Equation Modeling, 20, 616-639.

Reise, S.P. (2012). The rediscovery of bifactor measurement models. Multivariate Behavioral Research, 47, 667-696.

Rich, B.L., LePine, J.A., \& Crawford, E.R. (2010). Job engagement: Antecedents and effects on job performance. Academy of Management Journal, 53, 617-635.

Schaufeli, W.B., \& Bakker, A.B. (2004). Job demands, job resources, and their relationship with burnout and engagement: A multi-sample study. Journal of Organizational Behavior, 25, 293-315.

Schaufeli, W.B., Leiter, M.P., Maslach, C., \& Jackson, S.E. (1996). The Maslach Burnout InventoryGeneral Survey. In C. Maslach, S.E. Jackson, \& M.P. Leiter (Eds.), Maslach Burnout Inventory $3^{\text {rd }}$ ed. (pp. 19-26). Palo Alto, CA: Consulting Psychologists Press.

Shuck, B., \& Reio Jr., T.G. (2014). Employee engagement and well-being: A moderation model and implications for practice. Journal of Leadership \& Organizational Studies, 21, 43-58.

Shuck, B., Nimon, K., \& Zigarmi, D. (2017). Untangling the predictive nomological validity of employee engagement: Partitioning variance in employee engagement using job attitude measures. Group \& Organization Management, 42, 79-112.

Shuck, B., Zigarmi, D., \& Owen, J. (2015). Psychological needs, engagement, and work intentions: A Bayesian multi-measurement mediation approach and implications for HRD. European Journal of Training and Development, 39, 2-21.

Siegrist, J., Starke, D., Chandola, T., Godin, I., Marmot, M., Niedhammer, I., \& Peter, R. (2004). The measurement of effort-reward imbalance at work: European comparisons. Social Science \& Medicine, $58,1483-1499$.

Simbula, S., Guglielmi, D., Schaufeli, W.B., \& Depolo, M. (2013). An Italian validation of the Utrecht Work Engagement Scale: Characterization of engaged groups in a sample of schoolteachers. Bollettino Di Psicologia Applicata, 268, 43-54.

Skrondal, A., \& Laake, P. (2001). Regression among factor scores. Psychometrika, 66, 563-576.

Sonnentag, S. (2011). Research on work engagement is well and alive. European Journal of Work and Organizational Psychology, 20, 29-38.

Tein, J.-Y., Coxe, S., \& Cham, H. (2013). Statistical power to detect the correct number of classes in latent profile analysis. Structural Equation Modeling, 20, 640-657.

Tofighi, D., \& Enders, C. (2008). Identifying the correct number of classes in growth mixture models. In G.R. Hancock \& K.M. Samuelsen (Eds.), Advances in latent variable mixture models (pp. 317-341). Charlotte, NC: Information Age.

Tóth-Király, I., Morin, A.J.S., Bőthe, B., Orosz, G., \& Rigó, A. (2018). Investigating the multidimensionality of need fulfillment: A bifactor exploratory structural equation modeling representation. Structural Equation Modeling, 25, 267-286.

Uppal, N. (2017). Uncovering curvilinearity in the organizational tenure-job performance relationship: A moderated mediation model of continuance commitment and motivational job characteristics. Personnel Review, 46, 1552-1570.

van de Vijver, F., \& Hambleton, R.K. (1996). Translating tests: Some practical guidelines. European Psychologist, 1, 89-99. 
Veltrop, D.B., Molleman, E., Hooghiemstra, R., \& van Ees, H. (2018). The relationship between tenure and outside director task involvement. Journal of Management, 44, 445-469.

Warr, P. (1990). The measurement of well-being and other aspects of mental health. Journal of Occupational Psychology, 63, 193-210.

Wefald, A.J., Reichard, R.J., \& Serrano, S.A. (2011). Fitting engagement into a nomological network: The relationship of engagement to leadership and personality. Journal of Leadership \& Organizational Studies, 18, 522-537.

Yagil, D., \& Medler-Liraz, H. (2017). Personally committed to emotional labor: Surface acting, emotional exhaustion and performance among service employees with a strong need to belong. Journal of Occupational Health Psychology, 22, 481-491.

Zhong, L., Wayne, S.J., \& Liden, R.C. (2016). Job engagement, perceived organizational support, high-performance human resource practices, and cultural value orientations: A cross-level investigation. Journal of Organizational Behavior, 37, 823-844.

Zyphur, M.J. (2009). When mindsets collide: Switching analytical mindsets to advance organization science. The Academy of Management Review, 34, 677-688. 


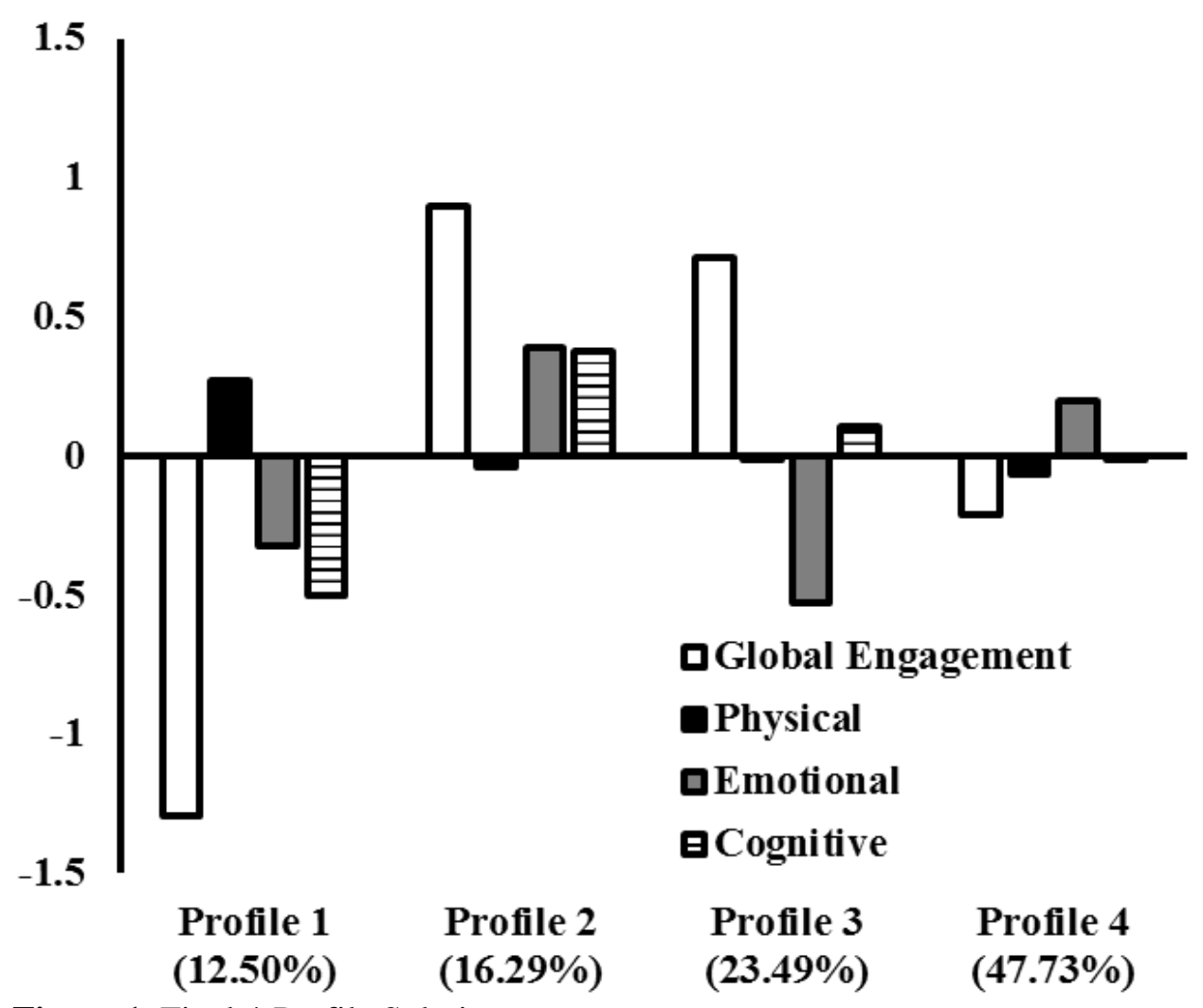

Figure 1. Final 4-Profile Solution

Note. Profile indicators are estimated from factor scores with a mean of 0 and a standard deviation of 1 ; Profile 1: Globally Disengaged; Profile 2: Globally Engaged; Profile 3: Globally but not Emotionally Engaged; and Profile 4: Moderately Engaged. 
Table 1

Results from the Latent Profile Analysis Models Based on Bifactor-ESEM Factor Scores

\begin{tabular}{lcccccccccc}
\hline Model & LL & \#fp & Scaling & AIC & CAIC & BIC & ABIC & Entropy & aLMR & BLRT \\
\hline 1 Profile & -1360.660 & 8 & 2.057 & 2737.319 & 2773.927 & 2765.927 & 2740.563 & Na & Na & Na \\
2 Profiles & -1045.350 & 17 & 1.719 & 2124.700 & 2202.491 & 2185.491 & 2131.592 & .990 & $<.001$ & $<.001$ \\
3 Profiles & -945.263 & 26 & 1.397 & 1942.526 & 2061.501 & 2035.501 & 1953.067 & .908 & .004 & $<.001$ \\
4 Profiles & -908.846 & 35 & 1.596 & 1887.692 & 2047.850 & 2012.850 & 1901.882 & .796 & .595 & $<.001$ \\
5 Profiles & -880.334 & 44 & 1.263 & 1848.668 & 2050.010 & 2006.010 & 1866.507 & .836 & .070 & $<.001$ \\
6 Profiles & -856.649 & 53 & 1.348 & 1819.298 & 2061.824 & 2008.824 & 1840.787 & .902 & .714 & 1.000 \\
7 Profiles & -815.323 & 62 & 1.264 & 1754.646 & 2038.355 & 1976.355 & 1779.784 & .887 & .529 & $<.001$ \\
8 Profiles & -833.006 & 71 & 0.896 & 1808.013 & 2132.905 & 2061.905 & 1836.799 & .942 & .729 & $<.001$ \\
\hline
\end{tabular}

Note: LL: model loglikelihood; \#fp: number of free parameters; Scaling: scaling factor associated with MLR loglikelihood estimates; AIC: Akaïke information criteria; CAIC: constant AIC; BIC: Bayesian information criteria; ABIC: sample-size adjusted BIC; aLMR: adjusted Lo-MendelRubin likelihood ratio test; BLRT: bootstrap likelihood ratio test.

\section{Table 2}

Associations between Profile Membership and the Outcomes

\begin{tabular}{lccccc}
\hline & Profile 1 & Profile 2 & Profile 3 & Profile 4 \\
& Mean [CI] & Mean [CI] & Mean [CI] & Mean [CI] & Significant Differences \\
\hline Affective commitment & $-1.102[-1.357 ;-.847]$ & $.481[.248 ; .714]$ & $.054[-.169 ; .277]$ & $.188[.004 ; .333]$ & $2>3=4>1$ \\
Normative commitment & $-.769[-.973 ;-.565]$ & $.314[.032 ; .596]$ & $-.105[-.346 ; .136]$ & $.196[.031 ; .361]$ & $2=4>3>1$ \\
Emotional exhaustion & $.296[-.004 ; .596]$ & $-.330[-.585 ;-.075]$ & $.312[.055 ; .569]$ & $-.112[-.269 ; .045]$ & $1=3>2=4$ \\
Ill-being & $.181[-.152 ; .514]$ & $-.482[-.633 ;-.331]$ & $.256[-040 ; .552]$ & $-.002[-.167 ; .163]$ & $1=3=4>2$ \\
\hline
\end{tabular}

Note. $\mathrm{CI}=95 \%$ confidence interval; affective commitment, normative commitment, emotional exhaustion, and ill-being are estimated from factor scores with a standard deviation of 1 and a mean of 0; Profile 1: Globally Disengaged; Profile 2: Globally Engaged; Profile 3: Globally but not Emotionally Engaged; and Profile 4: Moderately Engaged. 
Table 3

Results from Multinomial Logistic Regressions for the Effects of the Predictors on Profile Membership

\begin{tabular}{|c|c|c|c|c|c|c|}
\hline & \multicolumn{2}{|c|}{ Profile 1 vs. Profile 2} & \multicolumn{2}{|c|}{ Profile 1 vs. Profile 3} & \multicolumn{2}{|c|}{ Profile 1 vs. Profile 4} \\
\hline & Coef. (SE) & OR & Coef. (SE) & OR & Coef. (SE) & OR \\
\hline Gender & $-1.533(.741)^{*}$ & .216 & $-1.473(.690)^{*}$ & .229 & $-1.276(.646)^{*}$ & .279 \\
\hline Education & $.058(.447)$ & 1.060 & $-.227(.410)$ & .797 & $.020(.438)$ & 1.021 \\
\hline Working time & $-.566(.821)$ & .568 & $-1.750(.884)^{*}$ & .174 & $-1.249(.772)$ & .287 \\
\hline Tenure & $-.067(.482)$ & .935 & $.295(.431)$ & 1.343 & $.160(.469)$ & 1.174 \\
\hline Work autonomy & $-.300(.467)$ & .741 & $-.001(.400)$ & .999 & $-.248(.378)$ & .780 \\
\hline Task variety & $-1.670(.552)^{* *}$ & .188 & $-.962(.659)$ & .382 & $-1.189(.511)^{*}$ & .304 \\
\hline Task significance & $-.314(.444)$ & .731 & $-.122(.465)$ & .885 & $.112(.418)$ & 1.119 \\
\hline Task identity & $-.098(.544)$ & .907 & $.073(.615)$ & 1.076 & $.073(.527)$ & 1.076 \\
\hline \multirow[t]{3}{*}{ Feedback } & $-1.420(.540)^{* *}$ & .242 & $-1.189(.551)^{*}$ & .305 & $-1.478(.444)^{* *}$ & .228 \\
\hline & \multicolumn{2}{|c|}{ Profile 2 vs. Profile 3} & \multicolumn{2}{|c|}{ Profile 2 vs. Profile 4} & \multicolumn{2}{|c|}{ Profile 3 vs. Profile 4} \\
\hline & Coef. (SE) & OR & Coef. (SE) & OR & Coef. (SE) & OR \\
\hline Gender & $.060(.532)$ & 1.062 & $.257(.406)$ & 1.293 & $.197(.442)$ & 1.218 \\
\hline Education & $-.285(.301)$ & .752 & $-.038(.223)$ & .963 & $.247(.270)$ & 1.280 \\
\hline Working time & $-1.184(.896)$ & .306 & $-.683(.468)$ & .505 & $.501(.880)$ & 1.650 \\
\hline Tenure & $-.229(.294)$ & .795 & $.227(.215)$ & 1.255 & $.456(.220)^{*}$ & 1.577 \\
\hline Work autonomy & $.299(.429)$ & 1.349 & $.053(.381)$ & 1.054 & $-.247(.327)$ & .781 \\
\hline Task variety & $.708(.350)^{*}$ & 2.030 & $.480(.211)^{*}$ & 1.617 & $-.228(.396)$ & .796 \\
\hline Task significance & $.192(.347)$ & 1.212 & $.426(.278)$ & 1.532 & $.234(.272)$ & 1.264 \\
\hline Task identity & $.171(.350)$ & 1.186 & $.171(.259)$ & 1.187 & $.001(.320)$ & 1.001 \\
\hline Feedback & $.231(.441)$ & 1.260 & $-.058(.334)$ & .944 & $-.289(.355)$ & .749 \\
\hline
\end{tabular}

Note. $* p<.05 ; * * p<.01$; SE: standard error of the coefficient; OR: odds ratio; the coefficients and OR reflects the effects of the predictors on the likelihood of membership into the first listed profile relative to the second listed profile; work autonomy, task variety, task significance, task identity and feedback are estimated from factor scores with a standard deviation of 1 and a mean of 0 ; Gender is coded 0 for males and 1 for females; working time is coded 0 for part time workers and 1 for full time workers; tenure is coded in years; Education level was rated on a four-point scale ( $1=$ no diploma, $2=$ vocational training, 3 = high school, 4 = university); Profile 1: Globally Disengaged; Profile 2: Globally Engaged; Profile 3: Globally but not Emotionally Engaged; and Profile 4: Moderately Engaged. 


\section{Online Supplemental Materials for:}

\section{A Person-Centered Perspective on the Combined Effects of Global and Specific Levels of Job Engagement}

\section{Authors' note:}

These online technical appendices are to be posted on the journal website and hot-linked to the manuscript. If the journal does not offer this possibility, these materials can alternatively be posted on one of our personal websites (we will adjust the in-text reference upon acceptance).

We would also be happy to have some of these materials brought back into the main manuscript, or included as published appendices if you deem it useful. We developed these materials to provide additional technical information and to keep the main manuscript from becoming needlessly long. 


\section{A Brief Introduction to the Bifactor-ESEM framework}

When assessing the structure of responses obtained to typical psychometric measures, the CFA approach provides a way to assess the extent to which our a priori representations match the structure of responses obtained on an instrument, and even to compare alternative representations of the data based on objective fit assessment procedures. However, CFA rely on the independent cluster assumption that the latent constructs are unidimensional. More precisely, CFA assume that ratings obtained on any indicator reflect, or correspond, to scores on a single factor. This assumption has recently been shown to be overly stringent, and often unrealistic, for many psychometric measures (e.g., Marsh, Morin, Parker, \& Kaur, 2014). Morin and colleagues (Morin, Arens, \& Marsh, 2016; Morin, Arens, Tran, \& Caci, 2016; Morin, Boudrias et al., 2016, 2017) note that when conceptuallyrelated constructs (e.g., physical, emotional, and cognitive job engagement) are assessed within the same instrument, construct-relevant psychometric multidimensionality needs to be explicitly taken into account. Construct-relevant psychometric multidimensionality refers to additional sources of true score variance depicting associations between the items and non-target constructs that, when forcefully ignored in CFA, lead to biased estimates of the model parameter estimates (Asparouhov, Muthén, \& Morin, 2015; Morin, Arens. \& Marsh, 2016).

A first source of construct-relevant psychometric multidimensionality is particularly relevant to the job engagement construct and refers to the assessment of coexisting global and specific constructs. Psychometrically, two distinct approaches can be used to study this question. The most typical of these approaches relies on hierarchical models. In hierarchical models, ratings on specific indicators are used to define first-order factors (physical, emotional, and cognitive job engagement), which are themselves used to define a higher-order factor (global job engagement). However, hierarchical models rely on a stringent proportionality constraint according to which the ratio of variance explained by the global factor relative to that explained by the specific factors is forced to be exactly the same for all items associated with a specific first-order factor (Gignac, 2016; Morin, Arens, \& Marsh, 2016; Reise, 2012). Bifactor models provide a more flexible alternative not constrained by this unrealistic proportionality constraint (Chen, West, \& Sousa, 2006). In a $f$-factor bifactor model, one Global (G) factor (global job engagement) and $f-1$ orthogonal Specific (S) factors (physical, emotional, and cognitive job engagement) are used to explain the covariance among a set of $n$ items. Bifactor models directly test the presence of a global unitary construct underlying the answers to all items (G-Factor) and of co-existing specificities (S-Factors) not explained by the G-Factor.

A second source of construct-relevant psychometric multidimensionality likely to be present in measures of job engagement occurs when items designed to assess one specific construct present some degree of true score association with non-target constructs (Morin, Arens, \& Marsh, 2016; Morin, Arens, Tran, \& Caci, 2016). For instance, workers' levels of physical job engagement may influence responses to items designed to assess their levels of emotional or cognitive job engagement due in part to the naturally imperfect nature of these ratings, but also to the fact that the job engagement dimensions are interrelated conceptually (Rich, LePine, \& Crawford, 2010; Shuck, Nimon, \& Zigarmi, 2017). This form of construct-relevant multidimensionality calls for exploratory factor analyses (EFA) allowing for the free estimation of cross-loadings between items and conceptually-related constructs. EFA has recently been integrated with CFA and structural equation modeling into the ESEM framework (Marsh et al., 2014; Morin, Marsh, \& Nagengast, 2013), making it possible to consider that items tend to present at least some degree of valid association with more than one conceptually-related construct (Morin, Arens, \& Marsh, 2016; Morin, Arens, Tran, \& Caci, 2016). In particular, statistical research evidence (for a review, see Asparouhov et al., 2015) shows that excluding cross-loadings even as small as .100 tends to result in inflated estimates of the G-factor in bifactor-CFA or of factor correlations in CFA, whereas incorporating unnecessary cross-loadings has been shown not to result in estimation biases.

\section{Preliminary Analyses: Job Engagement}

CFA, bifactor-CFA, ESEM, and bifactor-ESEM representations of participants' ratings of job engagement were first estimated and contrasted. In CFA, each item was only allowed to load on the factor it was assumed to measure and no cross-loadings were allowed. This model included three correlated factors representing physical, emotional, and cognitive job engagement. In ESEM, the same set of three factors was represented using a confirmatory oblique target rotation (Asparouhov \& Muthén, 2009; Browne, 2001). 
Target rotation makes it possible to freely estimate all main loadings while targeting all cross-loadings to be as close to zero as possible. In bifactor-CFA, all items were allowed to simultaneously load on one G-factor reflecting global levels of job engagement, and on three $\mathrm{S}$-factors corresponding to specific levels of physical, emotional, and cognitive job engagement. No cross-loadings were allowed between the S-factors, and all factors were specified as orthogonal in line with bifactor assumptions (Morin, Arens, \& Marsh, 2016; Reise, 2012). Finally, bifactor-ESEM estimated the same set of G- and S-factors, while cross-loadings between the S-factors were estimated using an orthogonal bifactor target rotation (Morin, Arens, \& Marsh, 2016; Reise, Moore, \& Maydeu-Olivares, 2011).

Given the oversensitivity of the chi-square test of exact fit to sample size and minor misspecifications (Marsh, Hau, \& Grayson, 2005), we relied on goodness-of-fit indices to describe the fit of the alternative models: The comparative fit index (CFI), the Tucker-Lewis index (TLI), and the root mean square error of approximation (RMSEA) with its $90 \%$ confidence interval. According to typical interpretation guidelines (e.g., Marsh, Hau, \& Wen, 2004; Marsh et al., 2005; Hu \& Bentler, 1999), values greater than .90 and .95 for the CFI and TLI respectively are considered to be indicative of adequate and excellent fit to the data, while values smaller than .08 or .06 for the RMSEA respectively support acceptable and excellent model fit. In the comparison of nested models, typical guidelines suggest that models differing from one another by less than .01 on the CFI and TLI, or .015 on the RMSEA, can be considered to provide an equivalent level of fit to the data (Chen, 2007; Cheung \& Rensvold, 2002).

As noted by Morin and colleagues (Morin, Arens, \& Marsh, 2016; Morin, Boudrias et al., 2016, 2017), fit indices are not sufficient to guide the selection of the optimal model when first-order and bifactor ESEM and CFA models are contrasted. Indeed, each of these alternative models is able to absorb sources of construct-relevant multidimensionality left unmodelled, thus hiding sources of misfit behind apparently similarly fitting models (Asparouhov et al., 2015; Morin, Arens, \& Marsh, 2016; Murray \& Johnson, 2013). Thus, unmodelled cross-loadings tend to result in inflated factor correlations in CFA, or inflated G-factor loadings in bifactor-CFA. Likewise, an unmodelled G-factor tends to produce inflated factor correlations in CFA, or inflated cross-loadings in ESEM. For this reason, an examination of parameter estimates and theoretical conformity is required to select the best alternative. As suggested by Morin and colleagues (Morin, Arens, \& Marsh, 2016; Morin, Boudrias et al., 2016, 2017), model comparison should always start by contrasting CFA and ESEM solutions. Here, statistical evidence shows that ESEM provides more exact estimates of factor correlations when cross-loadings are present in the population model while remaining unbiased otherwise (Asparouhov et al., 2015). For this reason, and as long as the factors remain welldefined, the observation of a distinct pattern of factor correlations should be taken as support for the ESEM solution. The second step involves contrasting the retained CFA or ESEM solution with a bifactor alternative. Here, the key elements supporting the bifactor representation are the observation of a greater level of fit to the data, a well-defined G-factor, and at least some reasonably well-defined S-factors. The observation of multiple cross-loadings higher than .100 or .200 in ESEM that are reduced in bifactorESEM represents an additional source of evidence in favor of the bifactor solution (Morin, Arens, \& Marsh, 2016). For all models, we report standardized parameter estimates and composite reliability coefficients associated with each factor calculated using McDonald (1970) omega $(\omega)$ :

$$
\omega=\frac{\left(\sum\left|\lambda_{i}\right|\right)^{2}}{\left[\left(\sum\left|\lambda_{i}\right|\right)^{2}+\sum \delta_{i}\right]}
$$

where $\left|\lambda_{i}\right|$ are the standardized factor loadings in absolute values, and $\delta i$, the item uniquenesses.

\section{Preliminary Results: Job Engagement}

Table S1 of these online supplements presents the goodness-of-fit indices of the alternative measurement models. Parameter estimates for all solutions are reported in Table S2 of these online supplements. The CFA, ESEM, and bifactor-CFA solutions achieved an acceptable, and comparable, level of fit to the data according to all goodness-of-fit indices. Moreover, the bifactor-ESEM solution achieved an excellent fit to the data according to all goodness-of-fit indices, and a substantial increase in model fit relative to the bifactor-CFA $(\triangle \mathrm{CFI}=+.018 ; \Delta \mathrm{TLI}=+.008 ; \Delta \mathrm{RMSEA}=-.004)$, ESEM $(\Delta \mathrm{CFI}=+.020 ; \Delta \mathrm{TLI}=+.023 ; \Delta \mathrm{RMSEA}=-.010)$, and $\mathrm{CFA}(\Delta \mathrm{CFI}=+.038 ; \Delta \mathrm{TLI}=+.023 ; \Delta \mathrm{RMSEA}$ $=.010)$ solutions. Based on this statistical information, the bifactor-ESEM solution should be retained. However, as noted above, model selection needs to be based on a complete examination of the parameter estimates and theoretical conformity. Thus, we first compare the CFA and ESEM solutions, before comparing the ESEM and bifactor-ESEM solutions. 
ESEM versus CFA. Parameter estimates for the CFA and ESEM solutions are very similar, and reveal factors that are well-defined by strong factor loadings and satisfactory estimates of composite reliability (CFA: $\lambda=.596$ to $.884, M_{\lambda}=.779, \omega=.871$ to .921 ; ESEM: $\lambda=.365$ to $.948, M_{\lambda}=.691, \omega=$ .835 to .920$)$. When we look more carefully at the ESEM solution, despite the fact that multiple crossloadings are small and non-statistically significant (33 out of 36 possible cross loadings), many crossloadings remain non-negligible (6 cross-loadings are higher than .200). Although the presence of cross-loadings reinforces the need to incorporate this source of construct-relevant psychometric multidimensionality to the model, they also suggest that a global factor might be needed. Examination of the factor correlations associated with both of these solutions (see Table S3 of these online supplements) similarly reinforce the need to incorporate cross-loadings to the model, as these appear to be reduced in ESEM ( $r=.482$ to .778$)$ relative to CFA ( $r=.566$ to .893$)$.

ESEM versus Bifactor-ESEM. The bifactor-ESEM results reveal a G-Factor well-defined by strong and positive loadings from all items $\left(\lambda=.444\right.$ to $\left..819 ; M_{\lambda}=.657, \omega=663\right)$. Over and above this G-Factor, most items associated with the emotional $\left(\lambda=.482\right.$ to $\left..750 ; M_{\lambda}=.627, \omega=.881\right)$ and cognitive $\left(\lambda=.155\right.$ to $\left..501, M_{\lambda}=.364, \omega=.703\right) \mathrm{S}$-factors retain a satisfactory level of specificity. In contrast, the physical S-factor appears to be more weakly and inconsistently defined by most items $(\lambda$ $=-.352$ to $.447, M_{\lambda}=.009$ ), suggesting that physical ratings mainly serve to define global levels of job engagement. Still, the fact that this S-Factor retains less specificity than the other S-factors does not signify that this specificity is not meaningful, especially when models using an approach that explicitly controls for measurement errors and associations with the global job engagement construct. Indeed, this S-factor appears to retain at least some amount of specificity as illustrated by a non-negligible estimate of composite reliability $(\omega=.494)$. Finally, the superiority of the bifactor-ESEM solution is also apparent from the observation of reduced cross-loadings (only one cross-loading higher than .200 remains in the solution) relative to the ESEM solution. Factors scores for the person-centered analyses were thus extracted from the bifactor-ESEM solution.

\section{Preliminary Analyses and Results: Predictors and Outcomes}

Finally, a single measurement model was estimated to obtain factor scores related to all predictors and outcomes. In this model, three different set of ESEM factors were simultaneously modeled, one including five factors reflecting work characteristics (work autonomy, task variety, task significance, task identity, and feedback), two factors reflecting commitment to the organization (affective and normative commitment), and two factors reflecting psychological health (emotional exhaustion and illbeing). These factors were modelled using an oblique target rotation in which all factors loadings were freely estimated, all cross-loadings between items and factors from the same set of ESEM factors were freely estimated but "targeted" to be as close to zero as possible, and no cross loadings were allowed across sets of ESEM factors. This preliminary measurement model resulted in an acceptable level of model fit $(\mathrm{CFI}=.919$; $\mathrm{TLI}=.903$; RMSEA $=.051)$. Parameter estimates from this preliminary measurement model are reported in Tables S4 (Predictors) and S5 (Outcomes) of these online supplements, and the correlations among all variables are reported in Table S6 of these online supplements. Estimates of composite reliability obtained in this preliminary measurement model were fully satisfactory for all variables $(\omega=.779$ to .918$)$.

\section{References Used in this Supplement}

Asparouhov, T., \& Muthén, B. (2009). Exploratory structural equation modeling. Structural Equation Modeling, 16, 397-438.

Asparouhov, T., Muthén, B., \& Morin, A.J.S. (2015). Bayesian structural equation modeling with cross-loadings and residual covariances. Journal of Management, 41, 1561-1577.

Browne, M. (2001). An overview of analytic rotation in exploratory factor analysis. Multivariate Behavioral Research, 36, 111-150.

Chen, F.F. (2007). Sensitivity of goodness of fit indexes to lack of measurement. Structural Equation Modeling, 14, 464-504.

Chen, F.F., West, S.G., \& Sousa, K.H. (2006). A comparison of bifactor and second-order models of quality of life. Multivariate Behavioral Research, 41, 189-225.

Cheung, G.W., \& Rensvold, R.B. (2002). Evaluating goodness-of-fit indexes for testing measurement invariance. Structural Equation Modeling, 9, 233-255.

Gignac, G.E. (2016). The higher-order model imposes a proportionality constraint: That is why the bifactor model tends to fit better. Intelligence, 55, 57-68. 
Hu, L., \& Bentler, P.M. (1999). Cutoff criteria for fit indexes in covariance structure analysis: Conventional criteria versus new alternatives. Structural Equation Modeling, 6, 1-55.

Marsh, H.W., Hau, K.-T., \& Grayson, D. (2005). Goodness of fit evaluation in structural equation modeling. In A. Maydeu-Olivares \& J. McArdle (Eds.), Contemporary Psychometric (pp. 275340). Mahwah, NJ: Erlbaum.

Marsh, H.W., Hau, K.-T., \& Wen, Z. (2004). In search of golden rules: Comment on hypothesistesting approaches to cutoff values for fit indexes and dangers in overgeneralizing Hu \& Bentler's (1999) findings. Structural Equation Modeling, 11, 320-341.

Marsh, H., Morin, A., Parker, P., \& Kaur, G. (2014). Exploratory structural equation modeling: An integration of the best features of exploratory and confirmatory factor analysis. Annual Review of Clinical Psychology, 10, 85-110.

McDonald, R. (1970). Theoretical foundations of principal factor analysis, canonical factor analysis, and alpha factor analysis. British Journal of Mathematical \& Statistical Psychology, 23, 1-21.

Morin, A.J.S., Arens, A.K., \& Marsh, H. (2016). A bifactor exploratory structural equation modeling framework for the identification of distinct sources of construct-relevant psychometric multidimensionality. Structural Equation Modeling, 23, 116-139.

Morin, A.J.S., Arens, A.K., Tran, A., \& Caci, H. (2016). Exploring sources of construct-relevant multidimensionality in psychiatric measurement: A tutorial and illustration using the composite scale of morningness. International Journal of Methods in Psychiatric Research, 25, 277-288.

Morin, A.J.S., Boudrias, J.-S., Marsh, H.W., Madore, I., \& Desrumeaux, P. (2016). Further reflections on disentengling shape and level effects in person-centered analyses: An illustration exploring the dimensionality of psychological health. Structural Equation Modeling, 23, 438-454.

Morin, A.J.S., Boudrias, J.-S., Marsh, H.W., McInerney, D.M., Dagenais-Desmarais, V., Madore, I., \& Litalien, D. (2017). Complementary variable- and person-centered approaches to the dimensionality of psychometric constructs: Application to psychological wellbeing at work. Journal of Business and Psychology, 32, 395-419.

Morin, A.J.S., Marsh, H.W., \& Nagengast, B. (2013). Exploratory structural equation modeling. In G.R. Hancock \& R.O. Mueller (Eds.), Structural equation modeling: A second course ( $2^{\text {nd }}$ ed., pp. 395-436). Charlotte, NC: Information Age.

Murray, A.L., \& Johnson, W. (2013). The limitations of model fit in comparing the bi-factor versus higher-order models of human cognitive ability structure. Intelligence, 41, 407-422.

Reise, S.P. (2012). The rediscovery of bifactor measurement models. Multivariate Behavioral Research, 47, 667-696.

Reise, S.P., Moore, T.M., \& Maydeu-Olivares, A. (2011). Targeted bifactor rotations and assessing the impact of model violations on the parameters of unidimensional and bifactor models. Educational and Psychological Measurement, 71, 684-711.

Rich, B.L., LePine, J., \& Crawford, E.R. (2010). Job engagement: Antecedents and effects on job performance. Academy of Management Journal, 53, 617-635.

Shuck, B., Nimon, K., \& Zigarmi, D. (2017). Untangling the predictive nomological validity of employee engagement: Partitioning variance in employee engagement using job attitude measures. Group \& Organization Management, 42, 79-112. 


\section{Table S1}

Goodness-of-Fit Statistics of the Preliminary Measurement Models

\begin{tabular}{lccccc}
\hline \multicolumn{1}{c}{ Description } & $\chi^{2}(d f)$ & CFI & TLI & RMSEA & $90 \%$ CI \\
\hline CFA & $307.159(132) * .925$ & .913 & .071 & {$[.061 ; .081]$} \\
Bifactor-CFA & $245.884(117) * .945$ & .928 & .065 & {$[.053 ; .076]$} \\
ESEM & $237.272(102) * .943$ & .913 & .071 & {$[.059 ; .083]$} \\
Bifactor-ESEM & $172.311(87) *$ & .963 & .936 & .061 & {$[.047 ; .074]$} \\
\hline
\end{tabular}

Note. $* p<.01 ; \mathrm{CFA}=$ confirmatory factor analyses; ESEM $=$ exploratory structural equation modeling; $\chi^{2}$ : robust chi-square test of exact fit; $d f$ : degrees of freedom; CFI: comparative fit index; TLI: Tucker-Lewis index; RMSEA: root mean square error of approximation; $90 \%$ CI: $90 \%$ confidence interval for the RMSEA. 
Table S2

Standardized Factor Loadings ( $\lambda$ ) and Uniquenesses ( $\delta$ ) for the Preliminary Measurement Models

\begin{tabular}{|c|c|c|c|c|c|c|c|c|c|c|c|c|c|c|}
\hline & CFA & & B-CFA & & & ESEM & & & & -ESEI & & & & \\
\hline Items & $\lambda$ & $\delta$ & $\mathrm{G}-\lambda$ & $S-\lambda$ & $\delta$ & $\lambda$ & $\lambda$ & $\lambda$ & $\delta$ & $\mathrm{G}-\lambda$ & $S-\lambda$ & $S-\lambda$ & $S-\lambda$ & $\delta$ \\
\hline \multicolumn{15}{|l|}{ Physical } \\
\hline Item 1 & .676 & .543 & .670 & -.078 & .545 & .598 & .329 & -.111 & .437 & .698 & -.042 & .236 & -.107 & .444 \\
\hline Item 2 & .734 & .461 & .723 & -.221 & .429 & .948 & -.072 & -.135 & .345 & .755 & -.195 & -.077 & -.102 & .376 \\
\hline Item 3 & .794 & .369 & .789 & -.413 & .207 & .816 & -.041 & .043 & .316 & .803 & -.352 & -.058 & -.013 & .228 \\
\hline Item 4 & .690 & .524 & .738 & .274 & .380 & .381 & .024 & .323 & .541 & .724 & .293 & -.063 & .039 & .385 \\
\hline Item 5 & .596 & .645 & .646 & .371 & .445 & .365 & .027 & .224 & .672 & .654 & .447 & -.080 & -.061 & .362 \\
\hline Item 6 & .857 & .266 & .838 & -.108 & .286 & .515 & -.027 & .396 & .286 & .819 & -.095 & -.053 & .182 & .285 \\
\hline$\omega$ & .871 & & & .484 & & .835 & & & & & .494 & & & \\
\hline \multicolumn{15}{|l|}{ Emotional } \\
\hline Item 1 & .845 & .287 & .420 & .764 & .240 & -.089 & .939 & -.046 & .238 & .444 & .040 & .750 & -.020 & .238 \\
\hline Item 2 & .878 & .229 & .522 & .717 & .213 & -.066 & .890 & .073 & .209 & .542 & .046 & .701 & .032 & .212 \\
\hline Item 3 & .809 & .346 & .526 & .605 & .357 & .195 & .743 & -.111 & .347 & .550 & -.043 & .588 & -.073 & .345 \\
\hline Item 4 & .760 & .422 & .581 & .496 & .416 & .263 & .612 & -.036 & .409 & .597 & -.079 & .482 & -.031 & .404 \\
\hline Item 5 & .787 & .381 & .440 & .657 & .375 & -.145 & .830 & .089 & .367 & .455 & .096 & .645 & .020 & .367 \\
\hline Item 6 & .795 & .368 & .517 & .589 & .386 & -.017 & .715 & .143 & .386 & .513 & -.143 & .593 & .127 & .348 \\
\hline$\omega$ & .921 & & & .881 & & & .920 & & & & & .881 & & \\
\hline \multicolumn{15}{|l|}{ Cognitive } \\
\hline Item 1 & .796 & .367 & .715 & .349 & .367 & .161 & .086 & .613 & .372 & .707 & -.097 & .057 & .355 & .362 \\
\hline Item 2 & .741 & .451 & .710 & .222 & .446 & .160 & .052 & .580 & .453 & .698 & .142 & -.005 & .263 & .423 \\
\hline Item 3 & .879 & .228 & .755 & .470 & .209 & .021 & .021 & .860 & .214 & .740 & -.018 & .000 & .494 & .207 \\
\hline Item 4 & .884 & .218 & .756 & .483 & .194 & .009 & .034 & .867 & .205 & .742 & -.050 & .010 & .501 & .195 \\
\hline Item 5 & .864 & .253 & .765 & .393 & .261 & .049 & .069 & .787 & .256 & .752 & .034 & .025 & .417 & .259 \\
\hline Item 6 & .630 & .603 & .652 & .072 & .570 & .257 & .080 & .374 & .586 & .630 & .082 & .030 & .155 & .572 \\
\hline$\omega$ & .916 & & .956 & .659 & & & & .889 & & .663 & & & .703 & \\
\hline
\end{tabular}
factor; S: specific factor; $\lambda$ : factor loading; $\delta$ : item uniqueness; $\omega$ : omega coefficient of model-based composite reliability; target ESEM and B-ESEM factor loadings are indicated in bold; non-significant parameters $(p \geq .05)$ are marked in italics. 
Table S3

Latent Factor Correlations for the CFA and ESEM Solutions

\begin{tabular}{|c|c|c|c|c|c|c|}
\hline & \multicolumn{3}{|l|}{ CFA } & \multicolumn{3}{|l|}{ ESEM } \\
\hline & Physical & Emotional & Cognitive & Physical & Emotional & Cognitive \\
\hline Physical & - & & & - & & \\
\hline Emotional & .603 & - & & .564 & - & \\
\hline Cognitive & .893 & .566 & - & .778 & .482 & - \\
\hline
\end{tabular}

Note. All correlations are statistically significant $(p<.001)$. 
Table S4

Standardized Factor Loadings $(\lambda)$, Uniquenesses $(\delta)$, and Latent Correlations for the Predictors

\begin{tabular}{|c|c|c|c|c|c|c|}
\hline & WA & TV & TS & TI & FB & \\
\hline Items & $\lambda$ & $\lambda$ & $\lambda$ & $\lambda$ & $\lambda$ & $\delta$ \\
\hline WA 1 & .463 & -.008 & .025 & .266 & -.070 & .620 \\
\hline WA 2 & .337 & .184 & .132 & .350 & -.119 & .486 \\
\hline WA 3 & .632 & -.017 & -.051 & .081 & .015 & .566 \\
\hline WA 4 & .677 & .035 & -.048 & -.034 & .187 & .403 \\
\hline WA 5 & .717 & 147 & .142 & -.110 & -.031 & .337 \\
\hline WA 6 & .811 & .013 & -.050 & -.048 & .134 & 278 \\
\hline WA 7 & .792 & .068 & .080 & -.067 & -.141 & 406 \\
\hline WA 8 & .797 & -.142 & .043 & .008 & .008 & .436 \\
\hline WA 9 & .792 & -.119 & -.025 & .032 & .120 & .346 \\
\hline TV 1 & .086 & .761 & .053 & .029 & -.102 & .332 \\
\hline TV 2 & .094 & .796 & .037 & .031 & -.022 & 237 \\
\hline TV 3 & -.089 & .913 & -.016 & .056 & .146 & .143 \\
\hline TV 4 & .034 & .807 & .050 & -.013 & .075 & .243 \\
\hline TS 1 & .150 & .017 & .678 & -.123 & .060 & .426 \\
\hline TS 2 & .199 & .421 & .227 & -.046 & .088 & .492 \\
\hline TS 3 & -.070 & .061 & .628 & .099 & .030 & .562 \\
\hline TS 4 & -.009 & -.126 & .920 & .014 & -.006 & .229 \\
\hline TI 1 & .063 & .016 & -.061 & .550 & .089 & .606 \\
\hline TI 2 & -.156 & -.076 & .240 & .521 & .179 & .624 \\
\hline TI 3 & .036 & .097 & -.073 & .829 & .067 & 182 \\
\hline TI 4 & .251 & .036 & -.030 & .712 & -.010 & .230 \\
\hline FB 1 & .177 & -.039 & .066 & .165 & .503 & .466 \\
\hline FB 2 & -.050 & .088 & .094 & .059 & .793 & .256 \\
\hline FB 3 & .092 & .018 & -.015 & .028 & .837 & .184 \\
\hline$\omega$ & .903 & .918 & .779 & .806 & .834 & \\
\hline Correlations & 1 & 2 & 3 & 4 & 5 & \\
\hline 1. WA & - & & & & & \\
\hline 2. TV & .580 & - & & & & \\
\hline 3. TS & .421 & .374 & - & & & \\
\hline 4. TI & .549 & .319 & .208 & - & & \\
\hline 5. FB & .531 & .283 & .351 & .460 & - & \\
\hline
\end{tabular}

Note: $\lambda$ : factor loading; $\delta$ : item uniqueness; target ESEM factor loadings are indicated in bold; nonsignificant parameters $(p \geq .05)$ are marked in italics; $\mathrm{WA}=$ work autonomy; TV $=$ task variety; TS = task significance; $\mathrm{TI}=$ task identity; $\mathrm{FB}=$ feedback. 
Table S5

Standardized Factor Loadings ( $\lambda$ ), Uniquenesses $(\delta)$, and Latent Correlations for the Outcomes

\begin{tabular}{|c|c|c|c|c|c|}
\hline & AFF & NOR & $\mathrm{EE}$ & I-B & \\
\hline Items & $\lambda$ & $\lambda$ & $\lambda$ & $\lambda$ & $\delta$ \\
\hline AFF 1 & .911 & -.161 & & & .366 \\
\hline AFF 2 & .871 & .000 & & & .242 \\
\hline AFF 3 & .911 & -.057 & & & .245 \\
\hline AFF 4 & .622 & .211 & & & .370 \\
\hline AFF 5 & .772 & .103 & & & .273 \\
\hline AFF 6 & .553 & .208 & & & .476 \\
\hline NOR 1 & .300 & .518 & & & .405 \\
\hline NOR 2 & .236 & .660 & & & .271 \\
\hline NOR 3 & .107 & .743 & & & .315 \\
\hline NOR 4 & .025 & .824 & & & .289 \\
\hline NOR 5 & -.047 & .926 & & & .205 \\
\hline NOR 6 & -.086 & .832 & & & .408 \\
\hline EE 1 & & & 698 & .179 & .340 \\
\hline EE 2 & & & .860 & -.142 & .378 \\
\hline EE 3 & & & .830 & -.004 & .314 \\
\hline EE 4 & & & .868 & -.054 & .297 \\
\hline EE 5 & & & .497 & .253 & .548 \\
\hline I-B 1 & & & .327 & .332 & .660 \\
\hline I-B 2 & & & .155 & .463 & .681 \\
\hline I-B 3 & & & .000 & .630 & .603 \\
\hline I-B 4 & & & -.054 & .966 & .123 \\
\hline I-B 5 & & & .007 & .905 & .173 \\
\hline I-B 6 & & & -.071 & .953 & .162 \\
\hline$\omega$ & .916 & .915 & .882 & .883 & \\
\hline Correlations & 1 & 2 & 3 & 4 & \\
\hline 1. AFF & - & & & & \\
\hline 2. NOR & .760 & - & & & \\
\hline 3. EE & -.284 & -.092 & - & & \\
\hline 4. I-B & -.144 & .049 & .564 & - & \\
\hline
\end{tabular}

Note: $\lambda$ : factor loading; $\delta$ : item uniqueness; target ESEM factor loadings are indicated in bold; nonsignificant parameters $(p \geq .05)$ are marked in italics; AFF $=$ affective commitment; NOR $=$ normative commitment; $\mathrm{EE}=$ emotional exhaustion; I-B = ill-being. 


\section{Table S6}

Correlations between Variables

\begin{tabular}{|c|c|c|c|c|c|c|c|c|c|c|c|c|}
\hline & 1. & 2. & 3. & 4. & 5. & 6. & 7. & 8. & 9. & 10. & 11. & 12. \\
\hline \multicolumn{13}{|l|}{ 1. Global Job Engagement } \\
\hline 2. Physical Job Engagement & -.017 & & & & & & & & & & & \\
\hline 3. Emotional Job Engagement & .046 & .011 & & & & & & & & & & \\
\hline 4. Cognitive Job Engagement & .101 & .007 & -.061 & & & & & & & & & \\
\hline 5. Work Autonomy & $.341 * *$ & -.063 & $.423 * *$ & -.032 & & & & & & & & \\
\hline 6. Task Variety & $.411 * *$ & $-.132 *$ & $.342 * *$ & .004 & $.620 * *$ & & & & & & & \\
\hline 7. Task Significance & $.270 * *$ & $-.159 * *$ & $.252 * *$ & .028 & $.471 * *$ & $.416^{* *}$ & & & & & & \\
\hline 8. Task Identity & $.192 * *$ & $.186^{*}$ & $.244 * *$ & .077 & $.607 * *$ & $.357 * *$ & $.235^{* *}$ & & & & & \\
\hline 9. Feedback & $.267 * *$ & $-.155^{*}$ & $.307 * *$ & $.155^{*}$ & $.589 * *$ & $.322 * *$ & $.404 * *$ & $.524 * *$ & & & & \\
\hline 10. Affective commitment & $.423 * *$ & $-.142 *$ & $.441^{* *}$ & .087 & $.469 * *$ & $.401 * *$ & $.369 * *$ & $.333 * *$ & $.534 * *$ & & & \\
\hline 11. Normative commitment & $.238 * *$ & $-.156^{*}$ & $.305 * *$ & .076 & $.371 * *$ & $.314 * *$ & $.347 * *$ & .254 & $.420 * *$ & $.809 * *$ & & \\
\hline 12. Emotional Exhaustion & -.034 & $-.177 * *$ & $-.508 * *$ & -.034 & $-.249 * *$ & $-.122 *$ & -.060 & $-.294 * *$ & $-.232 * *$ & $-.306 * *$ & -.101 & \\
\hline 13. Ill-Being & -.096 & $-.212 * *$ & $-.444 * *$ & .030 & $-.237 * *$ & -.097 & .105 & $-.266 * *$ & $-.145^{*}$ & $-.152 *$ & .051 & $.602 * *$ \\
\hline
\end{tabular}

Note. $* p<.05 ; * * p<.01$; all variables are estimated from factor scores with a mean of 0 and a standard deviation of 1. 


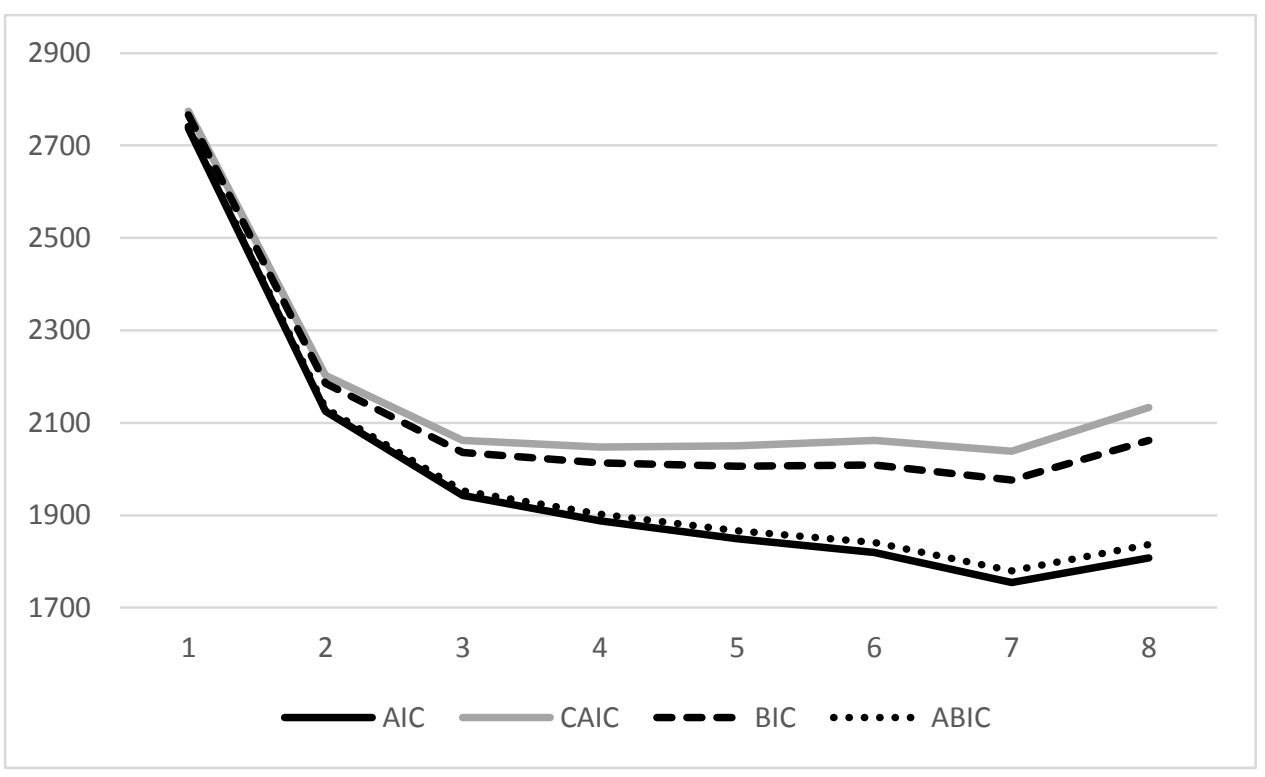

Figure S1

Elbow Plot of the Value of the Information Criteria for Solutions Including Different Number of Latent Profiles

Table S7

Detailed Results from the Final Latent Profile Analytic Solution

\begin{tabular}{|c|c|c|c|c|}
\hline & $\begin{array}{c}\text { Profile } 1 \\
\text { Mean }[\mathrm{CI}]\end{array}$ & $\begin{array}{c}\text { Profile } 2 \\
\text { Mean [CI] }\end{array}$ & $\begin{array}{c}\text { Profile } 3 \\
\text { Mean }[\mathrm{CI}]\end{array}$ & $\begin{array}{c}\text { Profile } 4 \\
\text { Mean }[\mathrm{CI}]\end{array}$ \\
\hline Global & $-1.292[-4.670 ; 2.086]$ & $.899[.890 ; .909]$ & $.712[.655 ; .769]$ & $-.209[-.914 ; .496]$ \\
\hline Physical & $.273[-1.632 ; 2.178]$ & $-.039[-.065 ;-.014]$ & -.011 [-.099; .077] & $-.068[-.230 ; .095]$ \\
\hline Emotional & $-.320[-1.134 ; .494]$ & $.391[.331 ; .452]$ & $-.530[-1.072 ; .013]$ & $.199[-.933 ; 1.330]$ \\
\hline \multirow[t]{2}{*}{ Cognitive } & $-.504[-2.156 ; 1.149]$ & $.374[.365 ; .383]$ & $.103[-.155 ; .361]$ & $-.014[-.353 ; .326]$ \\
\hline & Variance $[\mathrm{CI}]$ & Variance $[\mathrm{CI}]$ & Variance $[\mathrm{CI}]$ & Variance $[\mathrm{CI}]$ \\
\hline Global & $1.242[.169 ; 2.315]$ & $.001[.000 ; .001]$ & $.023[.013 ; .032]$ & $.492[-.008 ; .992]$ \\
\hline Physical & $2.344[-5.068 ; 9.755]$ & $.006[.002 ; .010]$ & $.039[.022 ; .057]$ & $.518[.068 ; .969]$ \\
\hline Emot & $1.193[-.625 ; 3.011]$ & $.020[.001 ; .038]$ & $1.931[.688 ; 3.174]$ & $.347[-1.092 ; 1.787]$ \\
\hline Cognitive & $1.713[-1.829 ; 5.255]$ & $.001[.000 ; .002]$ & $.375[.162 ; .589]$ & $.619[.073 ; 1.166]$ \\
\hline
\end{tabular}

Note. $\mathrm{CI}=95 \%$ confidence interval; the profile indicators are estimated from factor scores with a mean of 0 and a standard deviation of 1; Profile 1: Globally Disengaged; Profile 2: Globally Engaged; Profile 3: Globally but not Emotionally Engaged; and Profile 4: Moderately Engaged.

Table S8

Classification Accuracy: Average Probability of Membership into Each Latent Profile (Column) as a Function of the Most Likely Profile Membership (Row)

\begin{tabular}{lllll}
\hline & Profile 1 & Profile 2 & Profile 3 & Profile 4 \\
\hline Profile 1 & .701 & .000 & .007 & .292 \\
Profile 2 & .000 & .996 & .004 & .000 \\
Profile 3 & .000 & .008 & .951 & .041 \\
Profile 4 & .041 & .001 & .072 & .886 \\
\hline
\end{tabular}

Note. The profile indicators are estimated from factor scores with a mean of 0 and a standard deviation of 1; Profile 1: Globally Disengaged; Profile 2: Globally Engaged; Profile 3: Globally but not Emotionally Engaged; and Profile 4: Moderately Engaged. 